\title{
EL EXTRAÑO VIAJE DE G. A. COHEN (Y DE CIERTA CRITTICA MARXISTA AL LIBERALISMO IGUALITARISTA) *
}

\author{
Juan Manuel Pérez Bermejo \\ Universidad de Salamanca
}

RESUMEN. El filósofo marxista G. A. COHEN dirigió un ataque muy severo contra el liberalismo igualitarista de J. RAWLS. A su juicio, algunos argumentos de la obra de RAWLS, en especial el argumento de los incentivos al talento, justifican desigualdades que pueden llegar a ser muy acusadas. De hecho, el argumento de los incentivos se ha constituido en una de las principales coartadas a la hora de legitimar las políticas de desnivelación social que han acometido gobiernos de diverso signo. Este ensayo trata de mostrar que, en su legítima denuncia contra el fomento de la desigualdad, COHEN erró el blanco de su ataque: la filosofía política de RAWLS no sólo dispone de argumentos suficientes para denunciar las desigualdades acusadas, sino que los posee en mayor medida que la propia teoría de COHEN. Por último, la resistencia de la teoría de RAWLS a este tipo de críticas empujó a COHEN hacia tesis morales y metaéticas radicales, extremas e incompatibles con cualquier interpretación del marxismo.

Palabras clave: COHEN, RAWLS, incentivos, talento, liberalismo, intuicionismo, marxismo.

ABSTRACT. The Marxist philosopher G. A. COHEN launched a harsh attack against J. RAWLS' egalitarian Liberalism. In his view, some arguments of RAWLS' theory, especially his approval of incentives for talent, justify broad and considerable inequalities. Moreover, the incentives for talent became the main alibi for all the policies orientated to foster inequality and implemented by governments with different political badges. This essay attempts to prove that, in his legitimate denunciation of the growing inequality, COHEN chose the wrong target: RAWLS' political philosophy owns enough arguments to condemn broad inequalities, including some inequalities which would be inevitable from COHEN's theory. Finally, RAwLS' resilience against these sorts of criticisms pushed CoHEN's theory towards some moral and metaethical positions which can be judged as radical, extreme and incompatible with any interpretation of what we may call «Marxism».

Keywords: COHEN, RAwLs, incentives, talent, liberalism, intuitionism, marxism.

* Fecha de recepción: 15 de mayo de 2012. Fecha de aceptación: 18 de junio de 2012. 


\section{INTRODUCCIÓN: COHEN Y EL IGUALITARISMO SIN IGUALDAD}

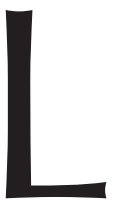

a obra de G. A. COHEN es una de las contribuciones más representativas del llamado «marxismo analítico», lo que equivale a decir que es un importante esfuerzo por elucidar los conceptos básicos del marxismo, ordenar lógicamente sus tesis más características y actualizar sus argumentos de acuerdo con los últimos desarrollos de la lógica y las ciencias sociales. Tras una primera etapa en la que interpretaba el marxismo como una teoría empírica, valorativamente neutra y meramente descriptiva de la estructura social o la dinámica histórica ${ }^{1}$, COHEN pasó a distinguirlo como una propuesta filosófica y normativa en torno a la moral pública, la política y la justicia. Es entonces cuando sus tesis políticas marxistas y fuertemente igualitaristas tropiezan con la filosofía moral y política más destacada de las últimas décadas: el liberalismo igualitarista de J. RAWLS. Desde entonces, COHEN es un filósofo «a la contra» cuyas obras se dedican en su mayor parte a someter a crítica los argumentos de RAWLS, una crítica en la que, de forma implícita o abreviada, aprovecha para formular sus ideas propias. En lo esencial, COHEN cree adivinar en el liberalismo de RAWLS una construcción teórica no ya insuficientemente igualitarista, sino legitimadora de la desigualdad social y económica.

El propósito de este artículo es desvelar cómo, aun compartiendo las inquietudes igualitaristas de COHEN, sus críticas al liberalismo político en general y al de RAWLS en particular sólo pueden sustentarse asumiendo otras tesis políticamente reprobables o, como es visible en sus últimos escritos, presumiendo una metaética desusada y en colisión flagrante con el núcleo teórico marxista.

Este propósito es compatible con un elogio a buena parte de las intuiciones morales y políticas que sirven de impulso a la obra de COHEN. De hecho, este ensayo presume que es razonable simpatizar con dos juicios sobre nuestras sociedades contemporáneas que son fácilmente reconocibles en este autor, y subyacen a todos sus argumentos: a) El nivel de desigualdad social y económica alcanzado por nuestras sociedades contemporáneas es moralmente escandaloso ${ }^{2}$. b) La pasividad ante la misma mostrada por gobiernos supuestamente comprometidos con el valor de la igualdad también es moralmente escandalosa.

Este último juicio exige una serie de aclaraciones que, como veremos, nos devolverán a la filosofía política de RAWLS.

Por supuesto, si la desigualdad ha alcanzado hoy un grado tan extraordinario no ha sido ni exclusivamente ni en su mayor parte por la pasividad de los gobiernos supuestamente igualitaristas. La responsabilidad alcanza a un buen número de gobiernos

1 Esta fase previa está representada por su obra de 1978 Karl Marx's Theory of History: A Defence. En un juicio retrospectivo, COHEN resumía su posición de entonces mediante una frase nítida: «En la medida en que me consideraba un marxista no me consideraba un filósofo» (COHEN, 1995: 2).

2 Asumiré este ensanchamiento de la desigualdad como un hecho palmario, y remito al lector a las estadísticas de la OCDE sobre desigualdad (especialmente en tasas de pobreza): bttp://stats.oecd.org/Index. aspx?DatasetCode=INEQUALITY. Sobre la actitud de COHEN, vid., por ejemplo, CoHEN, 2011: 61. Es lógico que una de las primeras recensiones a Rescuing Justice E Equality subrayara la «oportunidad» del libro en un contexto de «enormes rescates financieros, escalas tributarias planas, debilitamiento de las leyes protectoras del trabajador y, cómo no, aumento de la desigualdad» (BUCKLEY, 2010: 399) 
conservadores o neoliberales que, desde principios filosóficos y políticos muy distintos, han contemplado este incremento de la desigualdad desde la pasividad, cuando no desde la complacencia. La pasividad se explica si atendemos a que, desde sus posiciones filosóficas, es un error vincular el significado del concepto de justicia a imperativos de igualdad, de modo que la desigualdad no tiene por qué resultar moralmente perturbadora $^{3}$. La complacencia deriva de la aplicación de principios de justicia de carácter meritocrático, según los cuales lo justo es que los más talentosos, emprendedores o innovadores reciban más por sus habilidades y destrezas, y mucho más si éstas son extraordinarias. En el vocabulario de COHEN, esta concepción se asienta sobre el presupuesto de que el individuo es plenamente dueño de todas las creaciones y emanaciones resultantes de sus dotaciones físicas y mentales, de igual forma a como es plenamente dueño de sus órganos y facultades. COHEN denomina esta concepción la tesis de la auto-propiedad o self-ownership ${ }^{4}$. Esta tesis es, a su juicio, un error evidente: no hay merecimiento alguno en nuestras dotaciones naturales, un resultado azaroso que no atribuye créditos morales superiores. Además de evidente, es un error muy divulgado. Ha inficionado incluso al marxismo, cuya tesis de la explotación del trabajador mediante la plusvalía — la idea de que el trabajador, al desplegar su talento y su esfuerzo, entrega al capitalista una cantidad superior de la que está representada en su salario- parece presumir la auto-propiedad ya definida ${ }^{5}$. Y, por supuesto, se halla en el germen de la teoría y la práctica de los gobiernos neoliberales y conservadores que han protagonizado la gigantesca empresa de desnivelación social acometida en los últimos años.

En principio, los gobiernos más comprometidos con el valor de la igualdad que los neoliberales o conservadores no profesan la teoría de la auto-propiedad, ni son partidarios de teorías meritocráticas de la justicia. ¿A qué obedece entonces la pasividad que censuraba el juicio b? La explicación más verosímil es, precisamente, el blanco predilecto de la obra de COHEN: las llamadas «políticas de incentivos», y la teoría moral que las justifica. Estas políticas presumen que es socialmente necesario y moralmente correcto permitir un margen variable de desigualdad atendiendo a un hecho natural e incontrovertible de la psicología humana: nuestra tendencia a variar el ejercicio de nuestro talento y nuestro esfuerzo en función de la recompensa prevista. El espíritu de estas políticas es que aquellos que son capaces de generar mayor riqueza - por inteligencia, por capacidad inversora o, simplemente, por ocupar una posición social o laboral determinada - deben disfrutar de mayores rentas; de otro modo, se verían desincentivados en su trabajo, su productividad descendería, con ella la de toda la comunidad y, de ese modo, no sólo no sería posible elevar el nivel de vida de los más desfavorecidos, sino que, en la práctica, obtendríamos un empeoramiento de su situación. En virtud de este argumento, los gobiernos igualitaristas pueden enervar la crítica de pasividad aduciendo que su igualitarismo es sincero, pero que éste ha de ser inteligente y realista. El realismo impone la toma de conciencia de hechos naturales como la sensibilidad del esfuerzo humano al estímulo, la recompensa y los incentivos; por eso es frecuente escuchar que una teoría de la justicia ha de ser «sensible a la am-

\footnotetext{
NozICK, 1974: capítulos 7 y 8; 232 y ss.

${ }^{4}$ COHEN, 1995: 69 y ss.

5 Ibid., 121.
} 
bición» ${ }^{6}$. La inteligencia nos invita a considerar que el mejor modo de elevar el nivel de vida de los más desfavorecidos es incrementar el capital social, y que esta condición sólo es factible si los individuos y sectores más productivos de la comunidad son suficientemente recompensados.

COHEN considera que la teoría de la justicia de RAWLS es la justificación filosófica más poderosa que existe en favor de las políticas de incentivos y, con ello, de la paradójica conciliación entre un supuesto igualitarismo teórico y una legitimación práctica de desigualdades económicas considerables. Como hablamos de la teoría de la justicia más influyente de las últimas décadas, es posible afirmar que la cruzada de COHEN contra sus argumentos trata de ser también una cruzada contra la ideología de la desigualdad que, bajo denominaciones heterogéneas, ha dominado la política de los últimos decenios.

A primera vista, no faltan razones para afirmar que las acusaciones contra RAWLS son correctas. Como es sabido, su principio de justicia distributiva fundamental es el llamado «principio de diferencia», según el cual «las desigualdades sociales y económicas serán reguladas de tal modo que representen el mayor beneficio posible para los más desfavorecidos» ${ }^{7}$. Para RAWLS, la provisión para los más desfavorecidos de la mayor cantidad posible de rentas y riquezas es una razón moral en favor de mayores recompensas para los individuos más productivos. De hecho, RAWLS recurre literalmente a los términos «estímulo» e «incentivos» para explicar el funcionamiento del principio de diferencia y la justificación de desigualdades favorables a individuos cualificados por su mérito, talento o incluso por su posición social de empresarios ${ }^{8}$.

Sin embargo, pese a que sea razonable simpatizar con los motivos que condujeron a COHEN a formular su crítica a RAWLS, lo cierto es que ésta es insatisfactoria: a) No es cierto que aplicar la teoría de RAWLS nos aboque a desigualdades injustas; desde luego, las desigualdades compatibles con sus principios no revestirían el perfil escandaloso que presentan las que se han tolerado en los últimos años. b) La resistencia de RAWLS frente a sus críticas ha obligado a COHEN a reforzar progresivamente sus argumentos. Este reforzamiento le ha empujado hacia posiciones radicales y extremas en el ámbito de la teoría de la justicia y la metaética, lo que ha cobrado el efecto de desactivar la dimensión práctica de su crítica. c) La teoría de la justicia de COHEN es también compatible con desigualdades económicas profundas; más aún, el ámbito que RAWLS concede a la desigualdad es más justo que el asignado por COHEN.

En lo que sigue, me concentraré en la segunda de estas afirmaciones, y en su desarrollo se irán haciendo visibles las otras dos. Este trabajo se ordenará distinguiendo tres distintos frentes argumentales en los que COHEN le ha presentado batalla a la teoría de RAWLS, y que expondré sucesivamente en los tres epígrafes siguientes. El primer flanco de ataque puede localizarse en el liberalismo político de RAWLS, así como en la

\footnotetext{
6 KYMLICKA, 1990: 76. RAWLS (1971: 74n) incluye una explicación abreviada de estas políticas mediante el viejo principio aristocrático según el cual «si los de arriba tuvieran menos, los de abajo tendrían aún menos». Por supuesto, su punto de vista no se identifica con este principio.

7 RAWLS, 1971: 302.

8 «Las mejores expectativas concedidas a los empresarios les estimulan a realizar acciones que, a largo plazo, mejoran las perspectivas de la clase trabajadora». RAWLS, 1971: 78. Vid. también RAWLS, 2001: 63.
} 
limitación del alcance de sus principios de justicia a la estructura básica de la sociedad. El segundo se concentra en la dimensión contractualista de la teoría de RAWLS, especialmente en el criterio de racionalidad del contrato rawlsiano: la ganancia o el beneficio individual en un contexto de desinterés mutuo y habitado por individuos no afectados por los sentimientos de envidia o resentimiento. Por último, COHEN se posiciona en la discusión metaética, y censura el constructivismo de RAWLS desde una concepción firmemente intuicionista ${ }^{9}$.

\section{COHEN FRENTE AL LIBERALISMO POLÍTICO}

COHEN despliega esta crítica a lo largo de varios artículos, notas y aclaraciones que se publican durante más de veinte años. En la sección I), trataré de sintetizarla mediante algunos ejemplos de distribuciones que puedan dar idea de su mensaje más esencial. Siguiendo la estrategia de COHEN, tomaremos como modelo distribuciones $\mathrm{D}$ entre dos individuos representativos; A representará a los individuos más productivos o talentosos, y B a los menos aventajados ${ }^{10}$. En la sección II), reconstruiré la respuesta que, desde la teoría de RAWLS, puede dirigirse frente a las denuncias de COHEN.

I) 1. Supongamos una D1 igualitaria $(6,6)$. La dinámica social y económica tiende a alterar D1 del siguiente modo. El ciudadano A, merced a su mayor productividad, es capaz de lograr unas ganancias adicionales de ocho unidades, que, añadidas a las seis, le reportan 14. Estas ganancias pueden ser parcialmente fiscalizadas, lo que permitirá que el gobierno, mediante servicios o transferencias, entregue a B una unidad adicional. Resulta así D2 $(13,7)$.

Según Cohen, RaWls considerará D2 un cambio justo. Desde el punto de vista contractualista de la posición original, aprobamos aquello que beneficia a todos; ello equivale a afirmar que aprobamos cualquier cambio que cumpla con el principio de eficiencia u optimalidad paretiana, definido por RAWLS como el principio que aprueba aquella situación que beneficia a todos ${ }^{11}$. Es cierto que hay infinitos cambios o distribuciones nuevas que podrían ser eficientes o beneficiar a todos. El criterio que, según RAWLS, nos permite seleccionar entre estos posibles cambios igualmente eficientes es el llamado principio de diferencia, según el cual las ventajas diferenciales de A sobre B serán justas si y sólo si mejoran las expectativas de los más desfavorecidos o menos aventajados ${ }^{12}$. Éste es también el caso de la transición de D1 a D2: gracias a que A sale beneficiado, B también se beneficia. Finalmente, es cierto que D2 rompe con la igual-

9 De esta estructura no debe concluirse que COHEN defendiera cada uno de estos tres argumentos de forma sucesiva en el tiempo, en tres etapas que marcaran una supuesta evolución intelectual. Si esta evolución existe o no es un asunto complejo y que no será abordado en este ensayo. Por un lado, es posible distinguir en COHEN una evolución o una maduración de sus puntos de vista: por ejemplo, pasa de aceptar una «interpretación estricta» del principio de diferencia a rechazarlo totalmente. Por otro, es muy posible que buena parte de las opiniones expresadas en los epígrafes 3 y 4 fuesen suscritas por COHEN desde el principio. Sí resulta claro que esta distinción en tres frentes permite formular de un modo más claro y ordenado la variedad de principios y de argumentos implicados en su polémica con RAWLS.

10 Sobre individuos representativos: RAWLS, 1971: 64, 94-95.

11 Ibid., 66 y ss.

12 Ibid., 69. 
dad estricta o aritmética de D1; pero las distribuciones no necesitan ser estrictamente igualitarias para ser justas, sino, simplemente, redundar en beneficio de todos, y en especial de los más desfavorecidos ${ }^{13}$.

2. La pregunta que COHEN se formula entonces es ésta: dado que no hay una sola distribución más eficiente que D1, sino que podemos elegir entre varias adoptando como criterio el beneficio de B, ¿por qué justificar D2 cuando podemos redistribuir las ganancias mediante D3 $(10,10)$ ? D3 es también eficiente, representa una mayor ganancia para los más desfavorecidos, y resulta claramente más igualitaria.

3. COHEN conjetura que la respuesta de RAwls es bien simple: D3 es más justo que D2, pero normalmente no es una distribución empíricamente viable. Para que el paso de D1 a D3 sea viable, es preciso que los individuos sean capaces de incrementar el capital social en ocho unidades. El individuo A cuenta con el talento y la capacidad de esfuerzo necesaria para aportar estas ocho unidades. Pero, aunque técnicamente está capacitado para ello, no lo estará psicológicamente a menos que su mayor productividad sea suficientemente incentivada y recompensada. D3 incentiva insuficientemente al primer agente, porque le otorga las mismas recompensas que al agente menos capaz. De ese modo, no podemos esperar que acometa un mayor esfuerzo e impulse un cambio desde D1a D3.

4. La réplica de COHEN es, en este primer estadio de su ataque, una vindicación del principio de diferencia debidamente interpretado y, por tanto, una estrategia familiar o emparentada con la teoría de la justicia de RAWLS. El principio de diferencia establece que las únicas desigualdades admisibles serán las que puedan demostrarse como estrictamente necesarias para elevar el nivel de rentas y riquezas de los más desfavorecidos. Ahora bien, ¿de verdad es imposible que A pueda desplegar su talento y su esfuerzo si no obtiene una renta substancialmente superior a la de B? ¿Es el ser humano psicológicamente incapaz de movilizar su mayor capacidad si no se le incentiva con recompensas superiores?

A COHEN le parece obvio que no es así. En Europa, por ejemplo, la donación de sangre es un esfuerzo personal de una serie de voluntarios que no son retribuidos; en Estados Unidos, sin embargo, ha sido imposible establecer un sistema de este tipo, y las aportaciones de sangre son económicamente recompensadas. El fracaso del modelo europeo en Estados Unidos revela para COHEN que en Europa, al menos en el ámbito sanitario, existe en cada comunidad un ethos igualitario capaz de someter en algunos casos las exigencias egoístas de incentivos y recompensas ${ }^{14}$. Si este ethos igualitario ha podido constituirse en el ámbito sanitario, no hay ninguna razón para suponer que sea imposible extenderlo a otros ámbitos de la economía. D3 es factible cuando somos firmes y coherentes en la aplicación de nuestras concepciones igualitarias de la justicia. Por eso, nuestra reacción ante el individuo representativo A cuando exige elevar su nivel de rentas y su estatus social muy por encima del de B como condición para incre-

13 Ibid., 61

14 Cohen, 2008: 188 y ss. La mayoría de las referencias de este ensayo están tomadas de esta obra. Debe advertirse, sin embargo, que Rescuing Justice and Equality es una amplia recopilación de escritos publicados desde 1992, a los que se han añadido el capítulo 4 (especialmente relevante para nuestro epígrafe 3) y los capítulos 7 y 8 (relevantes en nuestro epígrafe 4). El libro es así una prueba de los distintos frentes ensayados por COHEN para distinguirse de la teoría de RAWLS. 
mentar el capital social y favorecer a los más desfavorecidos no debe ser la resignación: A se revela en este caso como un ciudadano egoísta e inmoral.

El primer error de la teoría rawlsiana es aceptar como presupuesto una determinada concepción científica o antropológica que identifica al ciudadano con el bomo oeconomicus que describe la microeconomía clásica, el egoísta de mercado propio de la economía capitalista y su particular esquema de motivos e intenciones. Por eso afirma COHEN que RAWLS suscribe en realidad una interpretación del principio de diferencia que no es «estricta», sino «laxa». Una interpretación estricta del principio de diferencia tolera únicamente, según COHEN, las desigualdades que sean objetivamente necesarias para mejorar la suerte de los más desfavorecidos, pero sin aceptar que las intenciones o los motivos de los agentes puedan determinar dicha necesidad. Frente a ello, la interpretación laxa, supuestamente favorecida por RAWLS, es ya dependiente de las intenciones de los individuos: «Si una desigualdad es necesaria para mejorar la suerte de los más débiles, pero sólo porque los individuos con más talento se están mostrando como maximizadores egoístas de mercado, entonces la desigualdad está autorizada por la interpretación laxa, pero prohibida por la estricta» ${ }^{15}$. A juicio de COHEN, RAWLS no duda en afirmar que estas desigualdades son necesarias, y que sin ellas no sería posible superar D1. Parece así suscribir la idea de MANDEVILLE y A. SмiтH, según la cual los vicios privados son necesarios para obtener beneficios públicos; el problema, afirma COHEN, es que MANDEviLLE no dudaba en calificarlos de «vicios», lo que no hace RAWLS ${ }^{16}$. En suma, COHEN no duda en afirmar que, debidamente interpretada, la justicia rawlsiana, presidida por el principio de diferencia, condenaría una política de incentivos para los más talentosos ${ }^{17}$, pero la presuposición de una antropología egoísta conduce a RAWLS a aceptarlos. Y el problema es que la aceptación de incentivos también implica contradecir algunas de las tesis más afortunadas de su obra.

En primer lugar, su admisión de una política de incentivos contradice todas sus advertencias sobre la lotería natural y social. RAWLS reitera que ninguna distribución debe estar determinada o condicionada por las contingencias naturales y sociales: cuán fuertes o inteligentes somos o en qué clase social hemos sido educados son circunstancias azarosas y aleatorias en las que no puede apreciarse valor moral alguno ${ }^{18}$. Sin embargo, el argumento de los incentivos otorga una serie de privilegios que están cualificados por la dotación física o intelectual del individuo representativo A, así como por el lugar que ocupe en las relaciones de producción. En la mayoría de los casos, el individuo representativo A será un individuo más productivo por su talento superior o por su mayor capacidad para el esfuerzo. En otros no es necesario que concurran estos requisitos: basta con que las contingencias de la organización social otorguen al individuo la posibilidad de maniobrar la relación entre salario y productividad, y chantajear al resto de la sociedad amenazando con dejar de trabajar si no se siente debidamente recompensado ${ }^{19}$.

\footnotetext{
15 COHEN, 2008: 68 y 69.

16 Ibid., 179.

17 «Estos individuos [los más talentosos] no necesitarían incentivos si estuvieran sinceramente comprometidos con el principio» de diferencia. COHEN, 2008: 32.

18 RAWLS, 1971: 71-73, 103-104; 2001: 74 y ss.

19 COHEN, 2008: 120.
} 
Aunque CoHen no la formule, podemos dar cuenta de una segunda anomalía: incorporar en el discurso la noción de «chantaje» desdibuja claramente otros argumentos clásicos de RAWLS, en concreto los que éste dirige contra modelos de contrato como los de HobBes, BUCHANAN o GAUTHIER, a los que acusaba de someter el resultado de los acuerdos políticos a la correlación de las fuerzas que exhiban sus negociadores. COHEN no vacila en calificar de «chantaje» la actitud de quienes reclaman incentivos: si compartimos la idea de que sobre A no pesa ninguna determinación psicológica, su negativa a desplegar su mayor talento a menos que se le otorgue un incremento substancial de rentas no es más que la explotación abusiva de su situación natural y social, y la amenaza de impedir el progreso de su comunidad. Se trata de un chantaje muchas veces revestido de hipocresía; los más talentosos suelen esgrimir que sus demandas redundan en beneficios para los más desfavorecidos: $\mathrm{B}$ terminará beneficiándose de los incentivos que cobre, de modo que ningún gobierno sensible a la pobreza puede dejar de atenderlos ${ }^{20}$. Además de hipocresía, estas estrategias de chantaje, soborno y amenaza admiten variaciones diversas: en ocasiones, es posible que $\mathrm{A}$, simplemente, alardee, y que amenace con dejar de hacer lo que en realidad está dispuesto a hacer sin incentivos; en otras, A puede encontrarse con un insospechado poder de negociación derivado de la falta de competencia en el mercado, o por golpes de fortuna diversos ${ }^{21}$. En todo caso, asistimos a una explotación de la correlación de fuerzas y de los poderes de negociación (o threat advantages) desiguales. RAWLS trató de representar el punto de vista moral correcto desde una posición original que, mediante recursos como el velo de la ignorancia, preservaban a los electores del influjo de la correlación de fuerzas desigual, y cerraban la puerta a la negociación o al bargaining ${ }^{22}$. Sin embargo, el bargaining y el aprovechamiento de los poderes de negociación desiguales parecen hallar una ventana abierta en el argumento de los incentivos.

Por último, y aunque de forma ambigua, COHEN cree que, dentro del caballo de Troya de los incentivos, la teoría de RAWLS esconde un ingrediente meritocrático. Para demostrarlo, recurre a una comparación erudita entre diversos pasajes de $A$ Theory of Justice y de algunas obras anteriores. COHEN concluye de sus comparaciones que RAWLS experimentó una evidente evolución: sus primeros escritos se limitaban a contemplar los incentivos como una necesidad empírica inevitable producto de las condiciones psicológicas de los seres humanos; sin embargo, A Theory of Justice afirma algo más,

${ }^{20}$ B se beneficia de que A «no vaya a la huelga», que declararía caso de que los incentivos se retiraran. COHEN, 2008: 33. COHEN llega incluso a comparar este argumento con el que a veces formula el secuestrador, que presenta el pago del rescate como un beneficio para las dos partes. «Si de verdad quieres a tu hijo, debes pagar» equivale a «si de verdad te importan los más desfavorecidos, es bueno que me pagues». «Hay una incongruencia similar cuando los ricos con talento se indignan con los partidos de izquierda por una supuesta falta de sensibilidad hacia los pobres que ellos aprecian en el hecho de que estos partidos traten de subirles los impuestos». COHEN, 2008: 63. Este tipo de manipulaciones, dice COHEN (2008: 47) son moralmente «repugnantes».

21 Cohen, 2008: 57. Para una discusión (crítica) de estas variaciones, vid. Pogge, 2000: 143 y ss. CoHeN (2008: 120) se muestra desdeñoso con esta segunda fuente de exigencias, dependiente de consideraciones empíricas «disputables». Creo que si concentra su denuncia en los incentivos por talento y desdeña los derivados de contingencias de la organización social es por dos razones. La primera es que el argumento de los incentivos por talento es el que amenaza más seriamente la coherencia interna del discurso de RAWLS. La segunda es que este desdén le permite eludir una discusión, por fuerza muy compleja, sobre algunas contingencias económicas y sociales que, como él mismo reconoce, sí justificarían algunas políticas de incentivos: por ejemplo, las que perseguirían eliminar trampas de pobreza. COHEN, 2008: 35.

22 RAWLS, 1971: 137. «A cada uno según su poder de negociación no es una concepción de justicia» (134). 
porque proclama el derecho de los más talentosos a rechazar el trabajo altamente productivo en ausencia de incentivos ${ }^{23}$. El argumento de los incentivos se transforma en un reconocimiento normativo de la relevancia moral del mayor talento. RAWLS acepta como justo que los más productivos obtengan más rentas que los menos productivos, y la justicia de esta relación implica una atribución de derechos a los más talentosos.

II) Antes de presentar nuestro esquema de respuestas, aprovecharé el orden de las críticas de COHEN para desactivar la última de ellas, que considero radicalmente errónea y fácilmente refutable. Esta crítica denuncia una cierta complicidad entre la teoría de RAWLS y las teorías meritocráticas de la justicia. Frente a esta crítica, podría aducirse de inmediato que para RAWLS los talentos naturales son moralmente irrelevantes, y añadirse que esta consideración es un «punto fijo» ${ }^{24}$, es decir, uno de los juicios morales emitidos en condiciones favorables para la reflexión y que, como el que proclama que la esclavitud es injusta, podemos considerar como más seguros y elementales. Sin embargo, esta respuesta no supondría para COHEN un serio quebranto: simplemente, esta idea es después contradicha por la aceptación de incentivos, que terminan justificando la mayor recompensa de los más productivos a causa de su mayor talento y en la medida en que demuestren su mayor talento. Ahora bien, el hecho de que los incentivos se atribuyan a las personas con mayor talento no significa que el argumento moral que los justifica se identifique con el hecho natural de su mayor dotación en inteligencia o capacidad: lo que es moralmente relevante en estos individuos no es una capacidad natural, sino la puesta a disposición de los más desfavorecidos de un excedente de capital social. Empíricamente, es muy posible que lo que distinga a estos individuos sea su mayor talento; moralmente, lo que convierte a estos individuos en acreedores de más rentas es la aportación de un mayor capital a los más desfavorecidos. Esta justificación moral de los incentivos no se concilia con la definición canónica de una teoría meritocrática. El análisis de G. SHER, referencia hoy habitual en el examen de estas cuestiones, revela que, en cualquier teoría meritocrática, el principio «a cada uno según su talento» construye una teoría estrictamente deontológica según la cual la distribución de un bien se resuelve mediante una conexión intrínseca entre el bien a distribuir y una cualidad de la acción o del estado mental de los individuos que lo hubieran creado, sin que importe otro tipo de consideraciones ${ }^{25}$. En la teoría de RAWLS, sin embargo, la conexión entre los bienes y el talento de quienes los crearan importa tan sólo instrumentalmente, sólo en la medida en que este talento sea invertido de forma que atribuya el mayor beneficio posible a los más desfavorecidos ${ }^{26}$. En suma, ni la justificación ralwsiana de los incentivos tiene una raíz meritocrática, ni la teoría misma encaja en la definición canónica de este tipo de teorías.

Salvada esta primera denuncia, la respuesta al alegato de COHEN podría estructurarse de este modo. Frente a las acusaciones de legitimar la desigualdad, la teoría

${ }^{23}$ CoHen, 2008: 177-180. «[Para RAWLS], los más talentosos tienen derecho a rechazar el trabajo productivo», 180.

${ }^{24}$ RAWLS, 1971: 104.

25 SHER, 1987: capítulo V.

26 «Las expectativas más elevadas de los mejor situados son justas si y sólo si funcionan como parte de un esquema que mejora las expectativas de los más desfavorecidos», RAWLS, 1971: 75, cursivas mías. Por eso, KyMLICKA completa la idea de que la teoría rawlsiana es sensible a la ambición con la idea de que es «insensible a las dotaciones naturales». KYMLICKA, 1990: 76. 
de RAWLS sostiene la preferencia de D3 $(10,10)$ sobre D2 $(13,7)$ siempre y cuando se satisfagan dos condiciones elementales: a) Que D3 sea factible. En contra de lo que piensa COHEN, RAWLS no descarta la viabilidad de D3, lo que invalida su denuncia de fundamentar su teoría de la justicia sobre una concepción antropológica que identifica al ciudadano con el bomo oeconomicus de la microeconomía clásica. b) Que las medidas que se adopten para lograr D3 no vulneren el esquema general de justicia, lo que incluye un principio prioritario que recoge un esquema de libertades individuales básicas. Como indicaré, las medidas favorables a la adopción de un ethos igualitario que propone COHEN infringen esta condición ${ }^{27}$.

a) Según el retrato que COHEN dibuja de la teoría de RAWLS, A no va a conformarse con D3 $(10,10)$, sino que va a reclamar D2 $(13,7)$, aun cuando aquélla beneficie en mayor medida a los menos afortunados. Según la lectura de COHEN, RaWLS juzga inevitable satisfacer esta pretensión, porque presume en los individuos una actitud egoísta que no sería corregible en una sociedad regida por su liberalismo político. COHEN atribuye a RAWLS una presunción científica: su teoría de la justicia se asienta sobre una concepción antropológica que identifica al individuo con el homo oeconomicus, el egoísta de mercado que es característico de las sociedades capitalistas. Esta presunción se enfrenta, desde luego, a otras piezas que son básicas en la teoría de RAWLS, y que parecen desmentirla. Así, en primer lugar, debemos apuntar la pieza que es constantemente señalada por COHEN: la supuesta neutralidad de la teoría de RAWLS. En efecto, el liberalismo político de RAWLS insiste en su independencia de doctrinas comprehensivas de carácter científico, lo que incluiría una concepción antropológica como la que aquí consideramos. Sin embargo, ¿cómo podemos explicar entonces que RAWLS se resigne a renunciar a D3, y juzgue imposible imponer a los gobiernos y a los ciudadanos un esfuerzo por alcanzarla si no es bajo la presunción de que A es un egoísta de mercado incorregible? Si no coactivamente, al menos la cultura política de una comunidad regida por el principio de diferencia o de favor a los más desfavorecidos podría persuadir a A de seguir aportando capital social a la comunidad y respetar los imperativos de igualdad; pero RAWLS también renuncia a que la cultura política cambie la conducta y la motivación de los individuos, y la única explicación es que RAWLS los juzga como irremediablemente egoístas. Es posible que RAWLS aspire a la mayor neutralidad posible ante las concepciones científicas, pero ello no le impide flexibilizar esa exigencia en el capítulo de los incentivos. Además de la neutralidad, nos permitimos señalar otras dos piezas del pensamiento de RAWLS que, a priori, parecen ser suficientes para impugnar las acusaciones de COHEN, pero que, en realidad, no logran desactivarlas. Así, en segundo lugar, RAWLS presume de los individuos dos poderes morales: en primer lugar «racionalidad» o capacidad para desarrollar y maximizar su concepción del bien, pero también «razonabilidad» o capacidad para constreñir la búsqueda del bien dentro de reglas generales o «términos justos de cooperación» que pueden imponen cargas ${ }^{28}$. El supuesto individuo egoísta y maximizador sin restricciones amparado por la esfera de lo racional se vería así limitado por la esfera de lo razonable, y el poder

${ }^{27}$ La discusión continúa con los modelos y pares distributivos propuestos por COHEN. Como se dirá en el siguiente epígrafe, el uso de estos modelos es problemático. Su misión será aquí meramente heurística: ayudar a formular algunos argumentos envueltos en la discusión.

${ }^{28}$ RAWLS, 1996: 50-51. 
de someterse a reglas que imponen sacrificios no compensados. Pero, en el caso de los incentivos, sucede que es la supuesta regla general o principio de diferencia la que, lejos de someter la persecución sin restricciones del bien individual, la legitima: RAWLS es un supuesto igualitarista que se opone a que los más talentosos exploten sus facultades superiores en su beneficio exclusivo; sin embargo, construye un principio que legitima precisamente que los mayores beneficios derivados del mayor talento no se vean restringidos por reglas generales o por supuestos principios y valores igualitarios, y que, además, les permite servirse estratégicamente de su mayor productividad para amenazar al resto de la comunidad con dejar de incrementarla si no obtienen recompensas suficientes. Lo razonable sólo sirve aquí para eliminar toda restricción a lo racional, lo que deja al desnudo al egoísta de mercado. Por último, sabemos que el régimen de atribución de recompensas o incentivos funciona en RAWLS dentro de una idea general de reciprocidad: puedo recibir más únicamente porque he contribuido más al bienestar de los más desfavorecidos ${ }^{29}$. RAWLS incluso refuerza la idea de reciprocidad, y liga los incentivos a una idea de fraternidad desde la cual, en una sociedad bien ordenada, los individuos, simplemente, no van a «querer» más ventajas a menos que ello redunde en beneficios para los más perjudicados ${ }^{30}$. Estas motivaciones no parecen propias de una teoría sujeta a concepciones egoístas. Sin embargo, creo que estas referencias dejarían de nuevo indiferente a COHEN o a sus seguidores: éstos interpretarían que la idea de reciprocidad no hace sino confirmar que este tipo de individuos son maximizadores sin restricciones que sólo están dispuestos a dar a cambio de que se les dé, y que se les dé más que a quienes aportan menos o nada a la colectividad. En suma, RAWLS presume una concepción egoísta del individuo, razón por la cual considera que: i) D3 (la igualdad) es imposible, y ii) D2 (la desigualdad) es justa e inevitable.

Sin embargo, ambas cosas son falsas: para RAWLS, D3 es factible muchas más veces de lo que supone COHEN y, cuando sea viable, será una opción más justa que D2. Y, si los efectos de la causa no se suceden, entonces deja de ser necesario recurrir a la supuesta causa de los mismos: la concepción antropológica. En cualquier caso, y de acuerdo con nuestros propósitos, más importante que negar el compromiso de RAWLS con esta concepción teórica es negar que su teoría legitime desigualdades cuantiosas, y menos aún desigualdades fundadas en circunstancias azarosas como el talento o el poder de negociación.

D3 es factible para RAWLS porque, en muchos casos, los individuos más talentosos estarán dispuestos a desplegar todos sus talentos y capacidades con independencia de que ello les reporte una mayor recompensa. Ésta es una idea que, paradójicamente, está enraizada en el entendimiento de que los individuos poseen el poder moral de la racionalidad y, por tanto, son maximizadores racionales de su propio bien. Su teoría formula esta idea mediante lo que denomina el «principio aristotélico», que no es sino una tendencia observable en los seres humanos a la hora de tratar de desarrollar sus concepciones del bien. El «principio aristotélico» afirma que los individuos prefieren desarrollar actividades más complejas y difíciles que otras más fáciles y rudimentarias, y ello «aun sin el incentivo de una recompensa evidente» ${ }^{31}$. De ese modo, los indi-

\footnotetext{
29 «El principio de diferencia incluye una idea de reciprocidad». RAWLS, 1971: 102; 2001: 122.

30 Ibid., 105.

31 Ibid., 426 y 432.
} 
viduos más talentosos, innovadores o emprendedores producirán más en beneficio de todos, y ello con independencia de que el cultivo de estas facultades les reporte mayores ingresos que a quienes no pueden cultivarlas: ellos se sienten satisfechos con la posibilidad de explotar estas capacidades y emprender estas tareas complejas. Esta idea encaja difícilmente con la descripción de agentes de mercado dispuestos a amenazar con no desarrollar sus talentos si no obtienen mayores ingresos. Si el principio aristotélico es correcto, muchos de los individuos con mayor talento se despreocuparán de reclamar incentivos y, caso de que lo hagan, un gobierno racional se limitará a negárselos, consciente de que los más talentosos preferirán seguir ejecutando las tareas complejas y minoritarias que les resultan más satisfactorias y, con ello, aportando un excedente de capital a la comunidad.

El principio aristotélico demuestra que, para RAWLS, D3 no es imposible. Ha de admitirse, sin embargo, que el alcance del principio aristotélico es limitado. RAWLS matiza que se trata de una mera tendencia, no de una ley natural, y que ésta es observable dentro de ciertas condiciones. Por ejemplo, es también parte del principio aristotélico la previsión de que el individuo más talentoso estará dispuesto a desarrollar sus capacidades superiores aunque ello le suponga desplegar un esfuerzo superior al que desarrollan quienes se limitan a desplegar capacidades inferiores; sin embargo, advierte que esto se verificará sólo dentro de ciertos límites o de un amplio número de variables: si el esfuerzo supera ciertos límites de dureza y exigencia, el individuo más talentoso, comprensiblemente, renunciará a acometerlo si no se ve recompensado ${ }^{32}$. Del mismo modo, si la productividad de los más talentosos es muy elevada, o si vislumbran la posibilidad de una recompensa muy cuantiosa, es posible que su advertencia de que no realizarán los trabajos más difíciles o complejos sea más que un alarde: en efecto, podría suceder que la idea de percibir mucho menos de lo que podrían les condujera a la decepción o la frustración, y, con ello, a renunciar total o parcialmente a dichas tareas. En cualquier caso, y pese a que RAWLS no contempla el principio aristotélico como una ley natural, su aceptación es suficiente para desmentir que su teoría de la justicia se construya desde la determinación científica proveniente de una concepción antropológica como la que COHEN describe.

Y, si D3 es factible, para RAWLS es muy claramente una opción más justa que D2. RAWLS afirma que un cambio distributivo debe ser eficiente, es decir, debe satisfacer la optimalidad paretiana, de forma que beneficie a todos o, en la versión subóptima, beneficie a alguien sin perjudicar a nadie. Ahora bien, como se ha dicho, hay infinitos cambios compatibles con la eficiencia. De hecho, D2 y D3 son igualmente eficientes respecto a D1. Por eso, RAWLS matiza el imperativo de eficiencia y suscribe la idea de que, de entre todos los cambios eficientes posibles, debe elegirse el que beneficie en mayor medida a los menos aventajados, tal y como demanda el llamado «principio de diferencia». Los más desfavorecidos disfrutan así de un privilegio de veto en los cambios distributivos: si éstos no les son favorables, con arreglo al principio de diferencia, cuentan con la facultad de impugnarlos independientemente de en qué medida favorezcan a los demás ${ }^{33}$. El ciudadano representativo B tiene razones para impugnar D2, porque D3 le es más favorable, y la teoría de RAwLS no duda en proclamar la mayor

\footnotetext{
32 Ibid., 1971: 428.

33 RAWLS, 1993: 282.
} 
justicia de D3 con respecto a D2. Y, si los argumentos de RAWLS son favorables a D3 frente a D2, no es correcto afirmar que RAWLS incluye una legitimación moral genérica del argumento de los incentivos, o que traiciona sus presupuestos igualitaristas ${ }^{34}$. $\mathrm{Al}$ contrario, la preferencia por los más desfavorecidos implica una corrección fuertemente igualitaria de los cambios eficientes que podamos considerar justos ${ }^{35}$.

Afirmamos antes que el principio aristotélico funciona dentro de ciertos límites y condiciones. Presumamos ahora un escenario en el que estos límites se han rebasado, y D3 no es factible. Este escenario no nos devuelve a las presunciones antropológicas del homo oeconomicus: la idea de que D2 es siempre inevitable o de que pesan determinaciones empíricas en su favor ha sido ya desmentida por el importante caudal de excepciones aportadas por el principio aristotélico. Más importante aún es subrayar que incluso el reconocimiento de que D3 $(10,10)$ es imposible no convierte la teoría de RAWLS en una ideología al servicio de la desigualdad y de las recompensas a los ciudadanos más talentosos o emprendedores. No lo es porque la desincentivación de A no tiene por qué conducirnos necesariamente al extremo de D2, sino que puede modularse mediante otras distribuciones $\mathrm{D} 3$ alternativas que podemos suponer como factibles: D3a $(9,9)$ y D3b $(8,8)$. RAWLS también justifica una preferencia general por estas variedades de D3 frente a D2. Esta preferencia vuelve a desmentir cualquier dependencia antropológica con el modelo del bomo oeconomicus, porque se trata de distribuciones estrictamente igualitarias (por eso las formulamos como variedades de D3) que frustran las expectativas más egoístas del ciudadano A. No sería admisible aducir que D2 es superior en bienestar agregado o en eficiencia a D $3^{36}$, y ello porque la equidad y la igualdad son en RAWLS prioritarias sobre el bienestar agregado y sobre la eficiencia. De hecho, creo que ésta es la forma correcta de interpretar la segunda regla de prioridad entre principios de justicia, formulada por RAWLS como la «prioridad de la justicia sobre la eficiencia y el bienestar» ${ }^{37}$. La justicia, como virtud suprema de la filosofía práctica, exige una teoría o concepción que ponga en orden un número muy amplio de consideraciones o de valoraciones morales ${ }^{38}$, entre las cuales, como hemos dicho, se incluye precisamente la eficiencia. Creo que esta regla de especificación de lo que es la justicia quiere decir que las consideraciones de equidad y de igualdad aproximada ${ }^{39}$ se imponen a las consideraciones de eficiencia y de bienestar. D3a o D3b son preferibles a D2 porque son más equitativas o igualitarias. RAWLS admite explícitamente que las consideraciones de igualdad y de beneficio de los más desfavorecidos implicarán a veces imponer un perjuicio neto a los más privilegiados que contravenga

34 CoHEN, 2008: 19.

35 Vid. la representación geométrica de RAWLS, 2001: 62 y 68.

36 En lo que se refiere al bienestar agregado, podría aducirse que D3a y D3b modelan sociedades con menor nivel de bienestar agregado que D2 (suman 18 y 16 unidades frente a las 20 de D2). En lo que se refiere a la eficiencia, tanto D2 como D3a y D3b son Pareto-superiores a D1, pues tanto A como B salen ganando en todas ellas. Sin embargo, si comparamos los dos cambios posibles, hay una razón para afirmar que D3a o D3b son cambios menos eficientes que D2: por adoptar D3a o D3b en lugar de D2, el ciudadano A pierde notablemente más de lo que B pierde si se hace lo contrario, y tiene así razones para impugnar dicho cambio. Más exactamente, por el hecho de preferir D2 a D3a o D3b, A gana 7 y B pierde 2 o 1 unidades respectivamente; preferir D3a o D3b a D2 supondrá que A pierde 4 o 5 unidades, y B gana 1 o 2 .

37 RAWLS, 1971: 302.

38 Ibid., 101 grafe 3 .

39 Las razones por las que identificamos equidad con igualdad «aproximada» se explicarán en el epí- 
las exigencias de la eficiencia ${ }^{40}$. Más fácil aún es descartar las consideraciones de bienestar agregado, celosamente criticadas por RAWLS en su larga denuncia contra el utilitarismo ${ }^{41}$. En suma, las razones que puedan oponer los más talentosos son desplazadas por consideraciones igualitaristas.

COHEN afirmaba que, en nuestras sociedades, nos resignamos con excesiva facilidad a la creencia de que las políticas de estímulo son necesarias e inevitables. Como hemos, visto, en RAWLS existen argumentos, como el principio aristotélico, que le permitirían estar de acuerdo con esta idea. COHEN añadía que es mucho lo que un gobierno asesorado por economistas y legisladores imaginativos y dotado de un aparato institucional eficaz puede poner en práctica para lograr que los más talentosos aporten su mayor capacidad en beneficio de toda la comunidad y, en especial, de los más desfavorecidos ${ }^{42}$. No hay razón alguna para sospechar que RAWLS no estaría de acuerdo una vez más: una política fiscal y económica inteligente puede aproximar cualquier distribución a D3 y, si ello no es posible, a D3a o D3b, modelos preferibles a D2 aunque supongan una pérdida relativa de eficiencia y bienestar agregado. RAWLS incluso especifica una receta política práctica, arraigada en su esquema de libertades básicas, para evitar algunas de las recompensas e incentivos señalados por COHEN: prevenir la consolidación de oligopolios e incrementar en la mayor medida posible la competencia entre los más talentosos, de modo que éstos «no puedan unirse como grupo y explotar su poder de mercado para incrementar su renta» ${ }^{43}$. El último RAWLS va incluso más lejos, y sostiene que un determinado tipo de libertades, las libertades políticas, deben poder ser disfrutadas por los ciudadanos en condiciones equitativas: no se trata sólo de que los ciudadanos ostenten por igual la titularidad de dichas libertades; debe también verificarse que el valor de dichas libertades, la posibilidad de uso y disfrute de las mismas, sea igualitario para todos los ciudadanos, con independencia de su posición social y económica; aunque RAWLS no profundiza en los cambios institucionales que implica esta exigencia, sí hace explícita la necesidad de combatir las grandes concentraciones de poder económico ${ }^{44}$. En suma, es mucho lo que un gobierno rawlsiano puede y debe hacer en favor de la igualdad y en contra de las reivindicaciones de desnivelación social basadas en incentivos al talento.

Ahora bien, sí existe un límite en la actuación del gobierno en favor de una distribución más igualitaria, y es el esquema completo de principios de justicia, lo que incluye la mayoría de las libertades básicas y la concepción liberal del Estado. Como veremos en la sección b), COHEN no está dispuesto a respetar este límite, y la consecuencia es transgredir exigencias morales inexcusables.

40 «Estos principios autorizarán cambios que pueden reducir las expectativas de los más aventajados. Por tanto, la concepción democrática de la justicia no es consistente con el principio de eficiencia si éste quiere decir que sólo son admisibles los cambios que beneficien a todos». RAWLS, 1971: 79.

${ }_{41}$ Vid., por ejemplo, RAWLS, 1971: 161-192; 207-209.

42 Puede, por ejemplo, explotar las motivaciones no pecuniarias de los individuos, como su deseo de destacar y de sobresalir (COHEN, 2008: 53; CARENS, 1981).

43 RAWLS, 2001: 67. La receta incluye no sólo combatir todo tipo de prácticas colusorias, sino imponer restricciones a las organizaciones colegiadas. Como afirma J. COHEN, buena parte de los problemas de desigualdad de nuestras sociedades son menos una cuestión de falta de ethos colectivo como un fracaso organizativo en la planificación de cuestiones más sencillas, como la política de los gobiernos ante la educación especializada o ante las organizaciones sindicales. J. COHEN, 2002: 374-375.

44 RAWLS, 2001, Sección 45. 
b) Supongamos ahora que $\mathrm{D} 3$ no es posible en ninguna de sus formas: no es posible alcanzar la distribución $(10,10)$, pero tampoco las representadas por D3a y D3b. De acuerdo con el principio aristotélico, considerando la posibilidad de soluciones igualitarias intermedias y que el modelo institucional de RAWLS prevé estimular la competencia de los más talentosos, podemos juzgar esta hipótesis como infrecuente. En cualquier caso, el dilema nos compromete a elegir únicamente entre D1 $(6,6)$ y D2 $(13,7)$.

Sin embargo, CoHEN nos pediría no apresurarnos en la formulación del modelo. Por extremas que sean las condiciones empíricas, que describen a A como un ciudadano radicalmente necesitado de incentivos, sería erróneo seguir juzgando las recompensas socialmente desniveladoras como estrictamente necesarias ${ }^{45}$. En realidad, COHEN sostendría que ni siquiera tenemos por qué conformarnos con fórmulas de compromiso como las representadas por D3a o D3b: podemos y debemos seguir aspirando a D3 $(10,10)$. Si RAWLS parece resignado a la imposibilidad de que A despliegue todas sus capacidades y se someta a una distribución igualitaria es, como sabemos, porque presume que las comunidades políticas están habitadas por el homo oeconomicus, y no por ciudadanos capaces de orientar su conducta privada hacia el beneficio de la comunidad y la plasmación de sus valores fundamentales. Por continuar con su ejemplo, RAWLS presume que su sociedad bien ordenada estará habitada por el donante de sangre norteamericano, y no por el europeo, y abriga esta presunción porque está convencido de que todos los individuos son como el donante de sangre norteamericano. Pero, en realidad, la diferencia entre Estados Unidos y Europa en relación con este ejemplo no está en los rasgos antropológicos de sus individuos: la diferencia es que en Europa está vigente un ethos comunitario, una cultura y unos valores igualitarios que orientan la acción pública y privada de los individuos, mientras que Estados Unidos, y la sociedad «bien ordenada» de RAWLS, carecen de él. El error de RAWLS no sería únicamente sustentar su teoría moral desde una antropología tan particular como errónea; más grave aún es negarse a introducir en su teoría los instrumentos morales, culturales e institucionales tendentes a apartar a los ciudadanos de las conductas insolidarias propias del egoísta de mercado. En realidad, RAWLS obstruye la adopción de este ethos mediante una serie de instrumentos teóricos. Para COHEN, el más importante de todos ellos es el carácter «dualista» de su teoría de la justicia, según el cual sus principios de justicia se limitan a regular y a diseñar las instituciones fundamentales del orden jurídico y político de la sociedad, lo que RaWLS denomina su «estructura básica». Confinados dentro de la estructura básica, los principios de RAWLS no son principios que puedan regir las acciones privadas de los ciudadanos, razón por la cual COHEN tacha su teoría de «dualista»: establece unos principios de justicia para las instituciones, y presume un régimen necesariamente distinto para el ámbito privado. En efecto, por este alcance limitado a la estructura básica, no son principios que puedan regular las distribuciones o las adjudicaciones de bienes que los individuos puedan decidir en sus relaciones privadas, en asociaciones particulares como la familia o la empresa: son principios públicos; tienen una dimensión jurídico-constitucional, porque funcionan como la parte más abstracta o el programa político más genérico que inspira la Constitución política de un Estado, pero no pueden ser movilizados de forma decisiva en

45 Cohen, 1971: 19. 
las acciones privadas o en las relaciones y asociaciones particulares que desarrollan los individuos. Sin embargo, advierte COHEN, las injusticias que se suceden en ámbitos privados como la familia o la empresa pueden frustrar la realización o la implantación de cualquier principio de justicia, incluidos los de RAWLS. Por ello, los principios no pueden limitarse a dar contenido a la parte más abstracta del orden jurídico: deben guiar las acciones de los individuos en todos sus ámbitos; y, para que esto sea posible, deben constituir algo más profundo que la Constitución o el orden jurídico: deben nutrir el ethos moral y cultural de la comunidad. Cumplido este requisito, D3 vuelve a ser factible, si bien ha de hacerse explícito que su contenido $(10,10)$ sólo puede ser resultado de la implantación de un ethos igualitario en la comunidad. Por esta razón, a partir de ahora, lo distinguiré como D3 plusethos.

No discutiré ahora si es empíricamente posible que un ethos igualitario sea capaz de superar eficazmente las limitaciones empíricas que rodean a D3. Me limitaré a sostener que RAWLS aporta razones convincentes para demostrar que D2 es más justo que este D3 plusethos.

Cualquier reflexión sobre este debate debiera comenzar perfilando con más precisión lo que COHEN denomina ethos comunitario. En un pasaje significativo, COHEN dice entender por ethos comunitario «el conjunto de sentimientos y actitudes en virtud de los cuales las prácticas habituales y las presiones informales son como son» ${ }^{46}$. Cuando habla de «presiones informales», COHEN se refiere a las respuestas críticas y a las sanciones informales del resto de la comunidad ante las acciones de los individuos, lo que incluye censura, desaprobación, indignación, rechazo de cooperación en el futuro u ostracismo. Podemos también inferir que dichas presiones informales actúan de forma auto-referencial, y se traducen en pesar, remordimiento o auto-reproche del individuo ante su propia conducta. En cualquier caso, la vigencia de una concepción de la justicia, piensa COHEN, no puede reducirse a la vigencia de una serie de principios de justicia para instituciones y, seguidamente, una serie de sanciones meramente jurídicas e institucionales contra sus infractores: implica también una vigilancia social y un enjuiciamiento permanente de cualquier acción individual de acuerdo con la métrica prevista en los principios de justicia. Por su parte, hablar de sentimientos y actitudes en la conformación de las prácticas sociales significa que el ethos comunitario es capaz de introducirse en el esquema de motivación de los individuos, y de moldear sus preferencias. La vigencia de una teoría de la justicia no se reduce a la proclamación de los principios políticos y jurídicos más abstractos y a la formulación de una serie de deberes institucionales: la concepción ha de gobernar también la esfera motivacional e incluso la esfera emocional de los individuos ${ }^{47}$.

El primer problema con el que tropieza COHEN es que su comunidad, conformada políticamente en torno a un ethos igualitario y un esquema motivacional altruista, es incompatible con un hecho que RAWLS cualifica con todo acierto como permanente

46 COHEN, 2008: 144.

47 Murphy interpreta que el ethos de COHEN se limita a afirmar que «en una sociedad justa será inevitable que algunos individuos tengan que tomar decisiones contrarias a su propio interés» (MURPHY, 1998: 266). Pero, como se ha visto, RAWLS sanciona esta misma exigencia. Más acertadamente, J. CoHEN explica que un ethos va más allá del problema de cómo nos tratamos los unos a los otros: es relativo a cómo vivir, y, por tanto, incluye lo que RAWLs llamaría una concepción del bien. J. COHEN, 2002: 365. 
e irreversible en las sociedades modernas, porque es una mera consecuencia del despliegue de la razón: el hecho del pluralismo, la coexistencia dentro de las sociedades de distintas concepciones morales sobre lo que es bueno — sobre los fines hacia los cuales los individuos debieran encaminar sus acciones públicas y privadas-, así como distintas concepciones o teorías sobre cómo son los individuos o las sociedades. Asumido este hecho, la comunidad de COHEN y su ethos igualitario se muestran igualmente incompatibles con algunas de sus consecuencias más importantes. En primer lugar, una sociedad plural de forma permanente e irreversible es una sociedad en la que, inevitablemente, coexisten doctrinas morales, políticas y filosóficas enfrentadas. De ese modo, la respuesta a la pregunta «¿qué es justo que los individuos hagan?» no puede resolverse insistiendo en la corrección que nosotros adjudiquemos a nuestra concepción del bien de acuerdo con nuestros criterios favoritos de justificación. Una concepción de la justicia que irrumpiera en este debate con la pretensión de ser la concepción de la justicia objetivamente correcta y la que, según algunos o muchos individuos, debiera ser promocionada por las instituciones porque es la que se infiere de sus criterios favoritos de justificación se convertiría en una parte más del problema social suscitado por el pluralismo, y no en la solución al mismo. Por eso la única solución al desafío que representan el pluralismo y el desacuerdo, que paralizan la adopción por la comunidad de cualquier principio de justicia, es una solución procedimental y consensual: será justo no lo que dicte un criterio predeterminado por cualquier doctrina comprehensiva que dote de contenido a los principios de justicia, sino lo que los ciudadanos acuerden a través de un procedimiento equitativo ${ }^{48}$. Sin que nos resulte de especial interés profundizar en el debate entre concepciones monistas y dualistas sobre la justicia, sí debe anotarse que RAWLS formula razones suficientes para justificar que la formulación de los principios de la moral política fundamental de las sociedades debe instanciarse a través de un procedimiento y un acuerdo ajeno a criterios de justicia previos e independientes; $y$, asumida esta idea, lo que se sigue de inmediato es que el resultado del acuerdo entre los individuos regirá en las instituciones que dan forma a los procedimientos de acuerdo y toma de decisiones sociales, es decir, en la estructura básica de la sociedad, mientras que los individuos pueden seguir sirviéndose de sus concepciones morales particulares para la resolución de sus problemas privados. La segunda consecuencia del hecho del pluralismo que resulta incompatible con la comunidad de COHEN es la neutralidad estatal, entendida ésta como la prohibición de que el Estado y sus instituciones básicas traten de imponer o de promocionar una determinada concepción del bien, así como de prohibir o de disuadir a sus ciudadanos de la persecución de otras ${ }^{49}$. Vulnerar la neutralidad supondría, como se ha dicho, presumir un criterio previo e independiente sobre la corrección de una concepción comprehensiva o particular. De hecho, el acuerdo más básico y fundamental destinado a resolver el problema de lo que es justo, el que llevan a cabo los individuos en la llamada posición original, termina considerando como la solución más racional para todos que los individuos disfruten en sus sociedades de un «derecho inderrotable a un conjunto suficientemente adecuado de libertades básicas compatible con la libertad de los demás» ${ }^{50}$. Este derecho al «más

48 RAWLS, 1971: 86

49 Es lo que RAWLS concreta como «neutralidad con respecto a los fines» del Estado: RAWLS, 1993: 192-194.

50 RaWls, 2001: 42. Cursivas mías. 
amplio esquema posible» ${ }^{51}$ de libertades consagra la imposibilidad de que el Estado realice pronunciamientos o desarrolle políticas favorables a una determinada concepción moral particular en detrimento de otras: los individuos son soberanos a la hora de elegir cuáles son sus concepciones morales sobre lo que es bueno o los fines mediante los cuales decidirán encaminar sus acciones privadas. Por el contrario, la comunidad de COHEN no podrá respetar esta soberanía. En general, decir «comunidad» o hablar de ethos «comunitario» supone ya hablar de una sociedad moralmente conformada y homogeneizada en torno a una serie de valores y de principios sobre lo que es bueno que los individuos hagan y persigan en sus vidas particulares. Estos principios integrarán también la acción y la política del Estado y de las instituciones, que deben promover o incluso imponer estos fines. En el caso particular de COHEN, estos principios o valores son valores igualitarios y altruistas. Es cierto que estos principios y valores están lejos de ser exhaustivos en lo que se refiere a lo que es bueno para los individuos. Sin embargo, no debe olvidarse que estos principios aspiran a gobernar la esfera motivacional y emocional de los individuos, lo que exigirá la intervención de las instituciones en la cultura pública y en el sistema educativo de los individuos con el fin de que adquieran el aprendizaje moral necesario. Para COHEN, los gobiernos no pueden ser indiferentes en torno a la decisión de, bien suministrar desde la infancia valores igualitarios y disposiciones a afrontar sacrificios no compensados en beneficio de la comunidad, bien no hacerlo así. Pero, en ese caso, la neutralidad estatal y la soberanía de los individuos en la elección de sus concepciones del bien resultan vulneradas ${ }^{52}$. No es así extraño que RAwLS declare incompatible su modélica sociedad bien ordenada y la idea de comunidad, entendida ésta como una sociedad gobernada por una doctrina moral particular ${ }^{53}$. En suma, el ethos comunitario de COHEN resulta discordante con dos tesis fundamentales del liberalismo político: a) Un Estado neutral, y no perfeccionista, respecto al problema de qué ideas del bien o qué concepciones del bien han de elegir y practicar los individuos. b) Si los individuos son en todo momento libres y autónomos para elegir y practicar su concepción del bien, sobre el Estado impera no sólo un principio de diferencia, sino otro que recoge el más amplio esquema posible de libertades individuales ${ }^{54}$.

Sin duda, CoHEN juzgaría esta argumentación como un sofisma destinado a encubrir una actitud de resignación ante el chantaje de los egoístas talentosos. En primer lugar el argumento vuelve a constatar un hecho supuestamente inevitable, permanente

51 RAWLS, 1971: 60.

52 COHEN puede estar en lo cierto cuando sostiene que su ethos comunitario no reclamará necesariamente de los individuos una actitud permanente de auto-sacrificio (2008: 10). Sin embargo, más preocupante que el grado de altruismo exigido por el ethos comunitario son los ajustes políticos que implica su inculcación.

53 RAWLS, 1993: 42. Cuál sea el ethos social o cultural dominante en una comunidad es un problema que debe ser resuelto mediante la crítica y el ejercicio de la razón dentro de la opinión pública o la esfera pública informal: J. COHEN, 2002: 385-386.

54 Es extraño que, cuando COHEN trata de demostrar que la teoría de RAWLS es incompatible con su ethos igualitario, identifica el obstáculo insalvable en el ámbito de su teoría, restringido a la estructura básica de la sociedad (COHEN, 2008: 25-26, 134 y ss). Existen en la teoría de RAWLS obstáculos más obvios y fundamentales: su liberalismo político y su primer principio de justicia. En ocasiones, COHEN alude a ellos, a veces tratando de conciliarlos con su punto de vista sobre el ethos comunitario (COHEN, 2008: 196-205), y otras oponiéndose a ellos sin ambages: de hecho, llega a afirmar que todas sus diferencias con RAWLS obedecen a que RAWLS es liberal, y «ésta es la profunda línea de división entre los dos» (COHEN, 2008: 2). Sin embargo, estas discusiones ocupan un espacio muy breve en comparación con el problema del ámbito de su teoría. Tal vez pueda sospecharse que este mutismo esconde cierta incomodidad. 
e irreversible —el pluralismo- que imposibilitaría un determinado tipo de políticas conducentes a un escenario de mayor justicia; en realidad, no hay ningún inconveniente fáctico que impida comenzar ejecutando ese tipo de políticas, beneficiarse de un modelo de sociedad mucho más justo y desenmascarar como egoístas inmorales a las minorías recalcitrantes que dicen profesar una concepción del bien alternativa, supuestamente menos igualitaria y altruista. En segundo lugar, COHEN minimizaría el alcance de sus políticas de promoción del ethos comunitario: estas políticas tienen un alcance muy sectorial, porque se limitan a hacer posible un determinado principio relativo a una de las muchas virtudes morales y políticas que están en juego en las prácticas de los individuos; la promoción del ethos comunitario se restringe a hacer posible el principio de diferencia debidamente interpretado, lo que sin duda es compatible con la vigencia de un amplio esquema de libertades individuales.

COHEN señalaba que el primer paso de nuestra argumentación, concentrado en el hecho del pluralismo, es puramente fáctico y contingente. Ello no es cierto por razones que se harán del todo explícitas en nuestro último epígrafe. Ahora, sin embargo, sí podemos completar el argumento anterior y subrayar que éste no se sostiene únicamente desde el hecho del pluralismo. Por ejemplo, si RAWLS afirma que nuestras sociedades no pueden ser «comunidades» en el sentido de COHEN, es decir, sociedades homogeneizadas en torno a una idea o concepción del bien, por limitado que sea su alcance, es porque ello se opone a nuestras ideas fuertemente arraigadas en nuestra cultura política sobre lo que es una sociedad justa. Ahora bien, estas ideas las obtenemos de una serie de intuiciones normativas fundamentales relativas a cómo nos vemos a nosotros mismos y cómo vemos a nuestras sociedades, y que funcionan como puntos de partida provisionales de la argumentación. Así, por ejemplo, nuestra forma de vernos a nosotros como ciudadanos nos describe como individuos libres capaces de distanciarse de su concepción del bien, de elegir ésta y, llegado el caso, de abandonarla, de modo que la elección de nuestra idea del bien sin interferencias estatales es en realidad una expresión de nuestra propia libertad. Por aportar otro ejemplo, nuestra forma de ver nuestras sociedades - nuestra concepción-«modelo» de una sociedad bien ordenada - se corresponde, según RAWLS, con la idea de un esquema cooperativo a largo plazo presidido por el concepto de reciprocidad. De ese modo, no consideramos correcta una concepción de la sociedad presidida por la idea de ventaja mutua, en la cual los individuos persiguen en todo momento maximizar su beneficio individual: tomamos como modelo sociedades que pueden exigir de sus individuos sacrificios no compensados. Pero, por otro lado, tampoco asumimos como correcta una concepción de la sociedad en la que sus individuos son altruistas movidos por el mayor bien de la comunidad como interés en todo momento superior a su propio bien individual, tal y como ocurriría en la comunidad de COHEN ${ }^{55}$. Finalmente, debe subrayarse que, como veremos en el último epígrafe, estas concepciones descansan en intuiciones normativas o juicios emitidos en circunstancias de especial consideración, lo que descarta su naturaleza fáctica.

En segundo lugar, la promoción o la implantación del ethos comunitario del que habla COHEN está lejos de ser tan parcial o restringida como para ser moralmente

55 RAWLS, 2008: 76-77. 
inocua, y sólo puede ser asumida al precio de transgredir principios y valores de justicia que ocupan un lugar crucial tanto en el sistema de principios de RAWLS como en cualquier sistema liberal y democrático bien fundado. Es posible que los argumentos relativos al principio de neutralidad estatal no sean para COHEN especialmente destructivos. Sin embargo, tal vez sea más preocupante denunciar que su ethos igualitario, conformado exclusivamente por su interpretación estricta del principio de diferencia, puede poner en riesgo las libertades básicas, y limitar la autonomía del individuo a la hora de construir su plan de vida ${ }^{56}$.

Se han señalado algunas consecuencias moralmente perturbadoras que COHEN habría de asumir desde su ethos comunitario ${ }^{57}$. Un trabajador puede conformarse con un puesto de trabajo en el que resulta mucho menos productivo y retribuido, pero que es más adecuado para su plan de vida por distintas razones: porque así vive más cerca de su familia o sus amigos ${ }^{58}$, o porque esa ciudad se concilia de mejor forma con su estilo de vida que otras. Muy posiblemente, estas razones serían juzgadas como egoístas por COHEN, o derrotadas por el notable perjuicio para los más desfavorecidos que estas decisiones conllevarían. Si la decisión de dónde trabajar puede convertirse en una decisión heterónoma, también la elección de la intensidad del trabajo puede correr la misma suerte. Si los más desfavorecidos lo demandan, el ethos comunitario podría justificar una especie de deber de trabajar duro, más allá de lo necesario para que el individuo preserve sus poderes morales ${ }^{59}$. Por último, cuando COHEN trata expresamente de demostrar que su ethos plasmaría la igualdad sin menoscabar el esquema de libertades básicas, sus explicaciones no logran despejar las dudas. Para ilustrar su punto de vista, COHEN propone un ejemplo que se concentra sobre una libertad específica: la libertad de ocupación. Supongamos que un individuo A está especialmente facultado para la medicina. Ahora bien, de trabajar como médico especialista, A ganaría $20.000 €$ al año, exactamente lo mismo que ganaría como jardinero, una profesión para la que también está capacitado, y que le proporciona la misma satisfacción que la profesión médica. Dado su esquema de razones y de motivaciones, A concluye lo siguiente: «Mientras el salario de un médico no alcance los $50.000 €$ al año, trabajaré

56 Han sido muchos los esfuerzos que han tratado de demostrar que la teoría de RAwLS es compatible o incluso presume como necesario un ethos comunitario. Se han propuesto distintos argumentos rawlsianos que podrían permitirlo: los principios para individuos, como el deber natural de justicia (COHEN parece apuntarse a esta idea en 2008: 9), la idea de fraternidad (de nuevo COHEN, 2008: 78, 131-132) o el llamado «sentido de la justicia» (Titelbaum, 2008: 294 y ss.). Por las razones ya expresadas, presumo que estos esfuerzos no son prometedores. Ahora bien, aunque fuese realmente posible conciliar la teoría de RAWLS con un ethos comunitario y las implicaciones que éste conlleva, comparto la tesis de TITELBAUM según la cual este ethos habría de ser un ethos integral y relativo a los dos principios de justicia, incluidas las libertades básicas y el principio de igualdad de oportunidades, lo que impugnaría el ethos que COHEN cree conformado exhaustivamente por el principio de diferencia estrictamente interpretado, y volvería a demostrar como moralmente preferible D2 frente al D3 plusethos en el sentido de COHEN.

57 Interpretamos aquí a COHEN como lo que RAWLS llamaría un liberal igualitarista comprehensivo, es decir, como un filósofo que trata sinceramente de conciliar igualdad, ethos comunitario y libertades básicas. Omitimos así acusaciones que conjeturamos como inconciliables con su planteamiento, como puede ser que un ethos igualitarista pudiera vulnerar principios democráticos, y postular gobiernos tecnocráticos (el gobierno de los economistas más capacitados para calcular el mayor beneficio de los más desfavorecidos) e incluso tiranías benevolentes (las cuales podrían producir «distribuciones más igualitarias que las que pudiera producir una democracia»: DWORKIN, 2000: 187).

58 Titelbaum, 2008: 322.

59 Ibid., 319. 
como jardinero, aun cuando dicho trabajo sea menos productivo y beneficie en mucha menor medida a los más desfavorecidos y a la comunidad en su conjunto». En principio, el caso describe una especie de trilema moral en el que sólo caben tres soluciones, cada una de las cuales menoscaba un valor moral importante: a) Aceptamos que el individuo sea jardinero, pero perjudicamos a los más desfavorecidos. b) Permitimos que trabaje como médico y elevamos su sueldo a $50.000 €$, lo que reproduce la dinámica perversa de los incentivos. c) Le obligamos coactivamente a que acepte trabajar como médico con sueldo de $20.000 €$ anuales. Las conjeturas anteriores podrían hacernos pensar que ésta es la solución favorita de COHEN. No es así: aunque la solución c) es una ganancia en igualdad, COHEN la tacha de «solución estalinista», y la rechaza por conculcar la libertad de ocupación ${ }^{60}$. El dictamen de COHEN sobre el caso es que el trilema es falso, porque existe una solución $d$ ) que permite reconciliar igualdad y libertad de ocupación, y que consiste no en obligar coactivamente a A a cultivar la medicina, sino en «persuadirle» de que ésta es la decisión correcta. En esencia, el mensaje de COHEN es que la libertad de ocupación es incompatible con la coacción, pero no con una «motivación moralmente orientada» ${ }^{61}$. Sin embargo, resulta obvio que el ejercicio de una libertad es un ejercicio de autonomía de la voluntad, y esta autonomía no es respetada si el esquema motivacional de A es secuestrado e intervenido desde la infancia. COHEN podría alegar que lo que presupone su ethos comunitario es simplemente la enseñanza moral de que debemos excluir de nuestras deliberaciones morales los sentimientos de egoísmo, envidia y resentimiento, los únicos que explican que A se niegue a realizar un trabajo socialmente más beneficioso e igualmente satisfactorio para él, y que también explican que adopte una actitud de chantaje hacia su comunidad exigiendo un incremento salarial muy notable como condición para convertirse en médico. Sin embargo, COHEN también rechazaría que el individuo, ante el problema de elegir entre dos profesiones igualmente remuneradas y placenteras, eligiera mediante una lotería exenta de este tipo de sentimientos: por ejemplo, lanzando una moneda al aire. El ethos comunitario no impone una serie de cláusulas procedimentales sobre cómo se debe elegir: impone la solución misma, de modo que resulta muy difícil hablar en este caso de autonomía y de libertad de ocupación. Éstos son tan sólo algunos ejemplos de cómo los conflictos entre el ethos comunitario y el esquema de libertades básicas son posibles e importantes, y de que existen razones morales para preferir D2 a D3 plusethos.

\section{COHEN FRENTE AL CONTRACTUALISMO}

Supongamos ahora que la necesidad de incentivar a los más talentosos es de nuevo acusada. La distribución inicial D1 $(6,6)$ puede ser modificada de dos formas. En el primer escenario incentivamos al ciudadano A cumpliendo mínimamente la exigencia de beneficiar a los más desfavorecidos, lo que deriva en la distribución D2 $(13,7)$; en el segundo, las recompensas son nulas o muy escasas, con la consecuencia de que la contribución de A disminuye ostensiblemente, y la distribución resultante es D4 $(7,7)$. La siguiente línea de ataque de COHEN frente a RAWLS sostiene que, a diferencia de la concepción rawlsiana, la suya es lo suficientemente igualitarista como para proclamar

\footnotetext{
60 Cohen, 2008: 183-187.

${ }^{61}$ Ibid., 198.
} 
que D4 es un modelo más justo que D2. Los argumentos pueden sintetizarse en dos: a) El valor de la justicia consiste, simplemente, en un trato o en una relación igualitaria, y no cabe duda de que $\mathrm{D} 4$ es un modelo distributivo más igualitario que $\mathrm{D} 2$. b) La justicia distributiva expresa un valor relacional o comparativo; que el ciudadano A posea mucho más que $\mathrm{B}$ es un dato del todo relevante para el enjuiciamiento moral.

Los argumentos $a$ ) y $b$ ) tratan de impugnar otros argumentos posibles en defensa de D2, y que, para COHEN, son especialmente importantes en la teoría de RAWLS.

En primer lugar, COHEN se opone a la tesis según la cual D2 es preferible a D4 porque satisface en mayor medida el criterio de racionalidad que declara como racional para un individuo lo que maximice su bien. Ésta es una tesis muy común si, como en el caso de RAWLS, defendemos un modelo contractualista de justicia. Desde este modelo, es justa aquella distribución que cuenta con la aprobación de los individuos afectados por ella. Ahora bien, una decisión colectiva no es más que un simple acto de voluntad, y los actos de voluntad pueden a veces conducir a consecuencias inmorales: necesitamos que la voluntad sea una voluntad racional, o, dicho de otro modo, necesitamos un criterio de racionalidad que establezca cuándo las partes del contrato están en condiciones de otorgar un consentimiento que conduzca a un resultado que podamos juzgar como moral o justo. En este caso, la doctrina contractualista propone el beneficio individual como el criterio que permite juzgar un consentimiento como racional; generalizando el criterio, podemos afirmar que un contrato es racional y deriva en un resultado moral o justo si supone un beneficio para todos los individuos que lo suscriben. Por último, debe observarse que los individuos que presume la teoría contractualista son maximizadores racionales cuya única motivación es aprobar lo que incremente en mayor medida su beneficio; otras fuentes de motivación, especialmente sentimientos como la envidia o el resentimiento (así como la benevolencia o el altruismo), resultarán perturbadoras en el esquema de un agente puramente racional.

La teoría de RAWLS sería un ejemplo perfecto de este modelo de justicia. Su intención es justificar sus principios de justicia mediante un aparato teórico contractualista $^{62}$. El principio de diferencia resulta de un contrato celebrado bajo las condiciones establecidas en lo que RAWLS llama la «posición original». Y en la posición original, asistimos a una descripción extensa de cómo funciona el criterio de racionalidad antes aludido. Los agentes eligen principios que maximizan su cuota de bienes primarios, y eligen desde los criterios de racionalidad y de cálculo suministrados por la teoría de la elección racional. Por último, los agentes eligen desde una indiferencia mutua que les inmuniza frente a los efectos de la envidia o el resentimiento, y concentran su elección en la maximización de su beneficio propio ${ }^{63}$. Desde estos criterios, los individuos elegirán D2: el ciudadano A sale claramente beneficiado, y $\mathrm{B}$, que no sale perjudicado, no contemplará con envidia la suerte de $\mathrm{A}^{64}$. Aun aceptando que $\mathrm{B}$ no sale ganando,

62 La justificación contractualista es la justificación «oficial» de sus dos principios: SCHEFFLER, 2003: 9.

${ }^{63}$ Los principios deben asegurar a todos los individuos más de lo que éstos obtendrían autárquicamente. Éste es uno de los argumentos de los que se sirve COHEN para dudar de que el contractualismo conduzca realmente a los principios de justicia que RAWLS propone: los ricos son perjudicados netos en su sociedad bien ordenada con respecto a una situación de autarquía. COHEN, 1995: 224-225.

64 Para RaWLS, «una distribución 5,10 es inequívocamente superior a una distribución 5,8; que la primera sea menos igualitaria que la segunda no es un argumento contra la misma». COHEN, 2008: 156-157. 
se cumple al menos con la versión débil del óptimo de Pareto: algunos ganan, y nadie pierde. Incluso podemos interpretar que $\mathrm{B}$ sale ganando, porque obtiene los beneficios del acuerdo y, con él, de inaugurar una relación cooperativa a largo plazo con A.

Para CoHEN, sin embargo, el razonamiento anterior sigue presuponiendo individuos egoístas propios de una economía de mercado. Lo que nos interesa ahora no es volver a considerar hasta qué punto, en el contexto de la sociedad bien ordenada, A miente o chantajea a B con la excusa de los incentivos, o hasta qué punto es o no factible obligarle a distribuir sus beneficios. Lo interesante es considerar los dos argumentos ahora novedosos, que COHEN interpreta como vinculados, y con los cuales, compone su alegato. COHEN se opone a un modelo contractualista de justicia y, con ello, separa ahora el valor de la justicia de los criterios de eficiencia o de optimalidad paretiana: si en otros momentos de su obra se mostraba preocupado porque sus soluciones respetaran los dictados de la optimalidad paretiana, ahora considera que la justicia no puede resolverse mediante un simple «todos salen ganando» o bien «algunos ganan, pero nadie pierde» ${ }^{65}$.

En segundo lugar, de acuerdo con el discurso que COHEN desarrolla en este segundo frente de ataque, el principio de diferencia no puede ser considerado ahora como un argumento suficiente para decidir entre modelos distributivos. Es cierto que la actitud de COHEN hacia el principio de diferencia es ambivalente, y que no faltan pasajes en los que sigue defendiéndolo en su interpretación estricta. Sin embargo, tampoco faltan otros en lo que manifiesta una marcada evolución en este punto, y expresa un claro distanciamiento del principio de diferencia, al que describe como «un resumen del principio Pareto» ${ }^{66}$. COHEN sospecha ahora que, fieles a la hipótesis de partida que hemos adoptado, el principio de diferencia se convierte en un instrumento legitimador del chantaje de A y de sus beneficios expresados en D2: el principio justificará D2 invocando los beneficios que a $\mathrm{B}$ le reporta firmar el acuerdo y entrar en cooperación con A, lo que no obtiene de insistir en D4; sin embargo, si D4 es imposible es, simplemente, porque $\mathrm{A}$ insiste en tener mucho más que $\mathrm{B}$, y amenaza con no suscribir el acuerdo si no se aceptan sus exigencias. De ese modo, podemos justificar la mejor cuota de A como una desigualdad necesaria para el beneficio de los más desfavorecidos. Sin embargo, COHEN interpreta que esta situación desafía nuestras intuiciones morales más elementales, que condenan la vasta desigualdad consagrada por D2.

Que RAWLS justifique tan amplias concesiones a los más talentosos termina traicionando dos de los pilares fundacionales de su teoría. En primer lugar, desafía de nuevo la intuición de que no hay mérito moral alguno en las dotaciones otorgadas por la lotería natural y social. En segundo lugar, desafía el lema fundacional de la teoría de RAWLS, la interpretación de la justicia como fairness. Esta teoría se presenta como un modelo de liberalismo igualitarista; sin embargo, D2 no es en absoluto un caso de relación igual y, desde luego, es un alejamiento ostensible de cualquier distribución igualitaria inicial ${ }^{67}$.

65 «Supongamos que la igualdad inicial es 5,5,5. En ese caso el primer individuo A puede prohibir un movimiento hacia 4,6,6. Pero, ¿por qué no puede prohibir también un movimiento hacia 5,6,6?... ¿Por qué, en otras palabras, no puede también prohibir los movimientos aprobados por el principio Pareto, pero que no le benefician?». COHEN, 2008: 164-165.

${ }_{66}$ Ibid., 30, n. 7.

67 «La distribución de rentas y riquezas no necesita ser igual, pero debe redundar en beneficio de todos». RAWLS, 1971: 61. «El principio de diferencia permite desigualdades moralmente arbitrarias... mi posición an- 
Las siguientes consideraciones tratarán de revalidar los dos argumentos ahora denostados por COHEN: el argumento contractualista y el principio de diferencia. Si estos argumentos conducen o no a justificar de forma genérica un modelo como D2 frente a D4 es una cuestión secundaria. Más relevante es devolver la confianza a los dos argumentos señalados y, especialmente, deshacer algunos malentendidos que anidan en las denuncias de COHEN.

Ya en el anterior epígrafe esbozamos una justificación mínima de lo que RAWLS denomina una teoría procedimental de la justicia, lo que implica la necesidad de que la concepción pública sobre la justicia sea independiente de las preconcepciones juzgadas por los individuos o los grupos particulares como buenas o correctas, y de que ésta resulte de un acuerdo entre los individuos. Un primer apunte que hemos de inferir de una teoría contractualista y procedimental de la justicia es que ésta no podrá confeccionar una concepción de la justicia de carecer rígido. Entiendo por una concepción «rígida» la que se expresa mediante un elenco tasado de principios y de reglas que se presumen capaces de resolver a priori y exhaustivamente todos los problemas de distribución que puedan plantearse en todos los niveles de la legislación o de la ordenación de la vida social. Una teoría rígida posee un principio capaz de resolver en abstracto, a priori y de forma general si D2 es siempre más justa que D4, o viceversa. En la teoría de RAWLS, sin embargo, se anticipa que los ciudadanos habrán de enfrentarse con problemas prácticos demasiado complejos como para que puedan ser resueltos mediante un elenco rígido de estándares. La teoría sí es capaz de formular un criterio supremo de distribución de bienes, como es el principio de diferencia, así como una serie de reglas de prioridad como las que comentamos en el epígrafe anterior. Sin embargo, cuando la sociedad bien ordenada se enfrente con problemas de distribución más concretos, o con la necesidad de dar contenido a una legislación precisa, tropezará con el problema de que la aplicación del principio de diferencia deberá combinar o poner en orden distintos valores o criterios morales relevantes para el problema específico de que se trate, sin que sea posible formular ex ante reglas de prioridad que los pongan en orden. Por recurrir a un ejemplo del propio RAWLS, algunos podrían pensar que el principio de diferencia es equivalente a un «principio de reparación» (redress), según el cual la acción del gobierno debiera encaminarse a corregir las discapacidades representadas por una menor inteligencia o un menor talento hasta aproximar el nivel cultural y educativo de los individuos en el mayor nivel de igualdad posible. RAWLS reconoce que hay un argumento correcto a favor de dicha suposición: el carácter moralmente irrelevante de las determinaciones naturales. Sin embargo, esta interpretación del principio de diferencia puede ser válida en algunas ocasiones, pero no en otras: puede ser válida para algunas políticas asistenciales, pero no, por ejemplo, para la determinación de los salarios ${ }^{68}$. El principio de reparación es tan sólo plausible como un criterio prima facie que ha de ser ajustado con otros valores o intereses que, como el de elevar el nivel de vida de los más desfavorecidos o el del bien común, podrán en ocasiones desplazarlo ${ }^{69}$. RAWLS también subraya que, cuando las circunstancias sociales cambian, el ajuste entre los distintos va-

terior era demasiado benévola... Siendo esto así, no podemos pensar que el principio de diferencia baste para ordenar la justicia distributiva». COHEN, 2008: $154 \ldots$ «No hay ninguna puerta trasera por la que podamos reintroducir la igualdad que el principio fairness empezaba favoreciendo». COHEN, 2008: 160.

68 RaWls, 1971: 308-209.

${ }^{69}$ Ibid., 100-101. 
lores e intereses también cambiará ${ }^{70}$. El criterio contractualista de justificación dispone que son los individuos quienes han de poner en orden el variado número de principios y de estándares moralmente relevantes que se pongan en juego en cada caso, y habrá de ser el uso de la razón pública quien conduzca a los individuos a un resultado justo. Por esta razón, la teoría de RAWLS no puede decidir de forma general entre alternativas numéricas de distribución que puedan plantearse de modo específico en la sociedad bien ordenada cuando ésta ha de dar contenido a sus leyes o sus reglamentos. Ello no convierte en improcedentes los razonamientos del epígrafe anterior: estos modelos de distribución son muy útiles como punto de partida heurístico para desplegar y hacer explícitos los argumentos que puedan ser más o menos relevantes en la teoría. Sin embargo, estos pares no pueden interpretarse como bancos de prueba con los que podamos resolver de forma previa, genérica y exacta los problemas de justicia distributiva que afecten al derecho positivo de la sociedad bien ordenada ${ }^{71}$.

Afirmar entonces que RAWLS patrocina la solución D2 frente a la solución D4 es una suposición muy apresurada. Es cierto que, como hemos visto, aplicar el principio de diferencia exige poner en orden una serie de valores entre los que se integra la optimalidad paretiana. Sin embargo, también hemos visto cómo la aplicación del principio de diferencia puede implicar la vulneración de aquél. En realidad, el razonamiento de COHEN sobredimensiona la importancia de la optimalidad paretiana dentro del razonamiento de RAWLS y, en general, en el de todo el contractualismo. COHEN presume que el criterio de racionalidad de cualquier forma de contractualismo es el criterio de la «ventaja mutua», según el cual el acuerdo se negocia entre individuos que persiguen maximizar su beneficio con indiferencia hacia la suerte ajena, y el acuerdo es racional cuando ambas partes salen ganando, o bien alguien gana y nadie pierde, lo que significa que el contrato puede declarar como justa una distribución que consagra desigualdades extremas ${ }^{72}$. RAWLS, sin embargo, rechaza que su modelo de contrato pueda ser clasificado como un modelo de «ventaja mutua». En su último escrito al respecto, RAWLS corrige expresamente cualquier malentendido que su obra anterior hubiese podido suscitar: su teoría de la justicia no es una parte de la teoría de la elección racional; no deriva únicamente del interés del individuo por maximizar su bien, sino de ideas o concepciones sobre la sociedad y el ciudadano que imponen fuertes exigencias de equidad al procedimiento; no es una teoría hobbesiana, sino una teoría kantiana ${ }^{73}$. El célebre velo de la ignorancia tiene por misión forzar a los electores a adoptar un punto de vista moral en el que se ha desactivado la influencia de cualquier diferencia natural y social entre los individuos; el resultado es que los individuos eligen con absoluta imparcialidad, porque lo que sea bueno para cada individuo será también bueno para la totalidad de los electores de la posición original ${ }^{74}$. COHEN se apresura

70 Ibid., 307.

71 «Una distribución no puede ser juzgada al margen del sistema institucional del que es resultado o de lo que los individuos hayan hecho de buena fe a la luz de las expectativas vigentes. Si se nos pregunta en abstracto si una distribución de un monto de bienes relativa a individuos con sus específicos deseos y preferencias es mejor que otra, en ese caso no hay respuesta a esta pregunta». RAWLS, 1971: 88.

${ }_{72}$ COHEN (2008: 111) llega a distinguir entre teorías contractualistas, ligadas a la optimalidad paretiana, y teorías imparcialistas de la justicia.

73 RAWLS, 2001: 82, n. 2.

74 «Cada uno elige necesariamente como si eligiera por todos». RAwLS, 1971: 140. El hecho de que las partes sean indiferentes hacia la suerte ajena no los convierte así en los maximizadores egoístas propios de la economía capitalista. RAWLS, 1971: 147-148. 
de nuevo cuando presume que la importancia de la optimalidad paretiana y el criterio contractualista conducen necesariamente a RAWLS a presumir D2 frente a D4.

Ahora bien, aun suponiendo que RAWLS patrocinara en algún o algunos casos D2 frente a D4, no creo que de dicha preferencia pueda concluirse que su teoría de la justicia termina traicionando el lema «justicia como equidad». En realidad, tampoco puede impugnarse por ello el carácter igualitarista de la teoría de RAWLS, ni siquiera afirmar que su igualitarismo es menos decidido que el de COHEN.

La defensa de estos juicios ha de empezar observando que el término «equidad» o fairness tiene un sentido distinto y más comprehensivo que el de igualdad estricta o aritmética. COHEN acusa al principio de diferencia de ser una pobre traducción del principio de equidad. Pero el principio de equidad se imputa no sólo al principio de diferencia, sino a todos sus principios, luego su significado es más abstracto del que presume. Aspirar a que los individuos sean tratados de modo equitativo es una aspiración a un trato igual y no discriminatorio, ajeno a ventajas indebidas de partida; como expresa SCHEFFLER, la equidad se vincula esencialmente con una igual ciudadanía, lo que supone así un estado de no opresión, no desconsideración o minusvaloración, así como con las actitudes que son necesarias para corregir las situaciones inicuas y opresivas, como la solidaridad y la ayuda mutua ${ }^{75}$. Desde esta descripción, el principio de diferencia tolera situaciones de desigualdad sin vulnerar por ello la equidad siempre y cuando atribuir más a algunos beneficie a los más desfavorecidos y, desde luego, siempre y cuando esta desigualdad no introduzca elementos de marginación, desconsideración u opresión en perjuicio de algún grupo de ciudadanos. RAWLS no deja de reconocer que, a priori, la distribución estrictamente igualitaria parece la forma más sencilla de resolver el problema de maximizar el beneficio de los más desfavorecidos. Aun en este caso, no puede dejar de observarse que la distribución igualitaria se impondría no porque adjudiquemos un valor moral prioritario a la igualdad aritmética, sino bajo el principio del mayor interés de los más desfavorecidos, para lo cual la distribución igualitaria sería un mero instrumento. Ahora bien, RAWLS es consciente de que esta presunción inicial se revelará muy frecuentemente como demasiado simple o rudimentaria cuando la enfrentamos con los complejos problemas sociales de distribución. En estos casos, existirán otras alternativas a la igualdad aritmética que maximicen el interés de los más desfavorecidos; y, cuando esto ocurra, el reparto aritméticamente igual habrá de interpretarse como una solución injusta ${ }^{76}$.

Hacer compatibles desigualdad y equidad parece militar de nuevo a favor de D2 y en contra de D4. Pero, como ya dijimos, las elecciones entre D2 y D4 se dilucidan en la sociedad civil, y han de ser dirimidas mediante un procedimiento de deliberación en el que los ciudadanos, no sometidos al velo de la ignorancia y conscientes de los valores e intereses que están en juego en cada problema específico, movilicen su razón pública y alcancen un acuerdo. Sin duda, algunos de los argumentos ya expresados fa-

75 SCHEFFLER, 2003: 21-22. La distinción podría ser equivalente a la que establece DwORKIN entre ser tratados como iguales, equitativamente, y ser tratados por igual. DWORKIN, 1978: 227.

76 RAWLS, 1971: 104-105. «Es normal sostener simplemente que, si uno no sabe nada en absoluto de un grupo de personas y tiene que adjudicarles unos bienes de algún modo... una solución respetuosa es dividir los bienes igualmente. Pero esta débil presunción desaparece por completo en cuanto hallamos cualquier razón para dar más bienes a uno o a otro». ARNESON, 2009: 18. 
vorecen que se consagre D2: es indiferente desde el punto de vista del beneficio de los más desfavorecidos, pero es eficiente o satisface el principio Pareto. Pero puede que concurran argumentos suficientes para apartar D2. Que el principio de diferencia sea el principio supremo en los problemas de distribución de bienes significa, como hemos visto, que los ciudadanos deben buscar el acuerdo que beneficie en la mayor medida posible a los más desfavorecidos. Elegir entre D2 y D4 exige así llegar a un acuerdo con los más desfavorecidos. La razón pública excluiría una oposición a D2 por parte del ciudadano representativo $\mathrm{B}$ motivada únicamente en el hecho de que A obtiene más que él: la justicia como equidad es compatible con situaciones de desigualdad; en este caso, imponer la igualdad se traduce simplemente en un perjuicio para $\mathrm{A}$ que no representa un beneficio para B. Sin embargo, B podría justificar su rechazo aduciendo que D2 impone un grado de desigualdad que resulta incompatible con los imperativos de la equidad. En efecto, la equidad no impone en todo momento una igualdad aritmética, pero es posible que la desigualdad alcance unos niveles acusados o afecte a instituciones tan sensibles que se traduzca en situaciones de marginación, desconsideración, dominio e incluso opresión de unos sobre otros, situaciones en las que ya no puede hablarse de igualdad de oportunidades, de acceso a cargos y responsabilidades, de bases suficientes de auto-respeto para todos o, en general, de trato igual ${ }^{77}$. Sin duda, estas impugnaciones no pueden ser una mera conclusión emotiva, sino que han de ser racionalmente argumentadas; pero, si esto último es posible, los más desfavorecidos están en condiciones de oponerse, y de impugnar distribuciones desiguales que son preferibles desde el punto de vista de la eficiencia y el bienestar general, pero más inicuas y, por tanto, injustas.

En suma, aunque el principio de equidad no es un principio de igualdad aritmética, aún permite impugnar distribuciones muy desiguales cuando éstas alcancen un nivel de marginación, desconsideración, opresión o división social. Sin embargo, no está tan claro que la teoría de COHEN pueda evitar estas consecuencias, y ello porque permite un ámbito de desigualdad nada desdeñable, y porque su obra no contiene instrumentos teóricos que puedan corregirla. En realidad, COHEN presume de reducir su teoría a unas pocas ideas sencillas e intuitivas: a) Justicia es igualdad. b) Algunas desigualdades sí son legítimas. Éstas se determinan mediante el criterio idiosincrásico de una corriente de teorías de la justicia rotulada como luck egalitarianism: son ilegítimas las desigualdades causadas por alguna determinación natural o social; están justificadas aquellas asignaciones o adscripciones desiguales cuyo origen sea imputable a actos de voluntad individual libre y autónoma. Por recurrir a los ejemplos más característicos, no son fuente admisible de desigualdad las dotaciones provenientes del talento, pero sí lo son las que derivan de la decisión libre del individuo de realizar un trabajo más penoso que el resto, de optar por un trabajo que exige un mayor tiempo de preparación (como el estudio de una carrera universitaria) o, simplemente, de incrementar su esfuerzo y trabajar más horas que los demás ${ }^{78}$. Estos capítulos permiten

77 «Aunque, en teoría, el principio de diferencia permite en general grandes desigualdades a cambio de pequeñas ganancias para los más desfavorecidos, en la práctica la extensión de la desigualdad de rentas y riquezas no será excesiva dadas las condiciones del trasfondo institucional». RAWLS, 1971: 470. Si la desigualdad sitúa a los más desfavorecidos en desventaja con respecto a las instituciones y al derecho, el acuerdo de distribución deberá ser impugnado.

${ }^{78}$ COHEN, 2008: 56, 126, 181. 
blanquear desigualdades muy cuantiosas, suficientes para consagrar jerarquías y divisiones sociales profundas, y frente a las cuales la teoría de COHEN, respetuosa con este tipo de ganancias, no parece oponer resistencia. De este modo, también hay razones para concluir que, sin necesidad de establecer equivalencias entre justicia, equidad e igualdad aritmética, el igualitarismo de RAWLS puede demostrarse en ocasiones como más robusto que el de COHEN; no es cierto que el contractualismo le haga retroceder en igualitarismo, y tampoco que le someta en todo momento a los imperativos de la eficiencia y la optimalidad paretiana.

\section{COHEN FRENTE AL CONSTRUCTIVISMO}

La ruptura de COHEN con la teoría de RAWLS se consuma cuando sostiene preferencias claramente rechazadas por el principio de diferencia: «¿Por qué $(10,6) \ldots$ es más equitativo que $(5,5)$ ?... Cuando observamos que $(10,6)$ beneficia de hecho al más desfavorecido, aún así, nuestras razones para pensar que es una distribución injusta permanecen» ${ }^{79}$. Sin duda, cualquier modelo contractualista rechazaría por irracional un juicio como el que COHEN acaba de formular, e incluso observaría que un mínimo de sensatez conduciría a los electores a preferir $(10,6)$ a $(5,5)$, y a considerarlo más justo. Pero COHEN se enfrenta ahora no ya con el modelo contractualista y la posición original, sino con todo el esquema teórico que RAWLS ideó para justificarlos, fundamentalmente lo que COHEN denomina el método constructivista de justificación y el equilibrio reflexivo. Ahora bien, si, para COHEN, la justicia implica preferir $(5,5)$ a $(10,6)$, se verá asaltado de inmediato por dos preguntas urgentes: $a$ ) ¿Cómo es posible sustentar un juicio sobre lo que es justo en contra de las preferencias y de los intereses de todos los individuos involucrados? La distribución que COHEN propone ahora no es factible porque una política que no contara con el consentimiento de los ciudadanos representados no sería realizable. b) Si su juicio no se justifica mediante un acuerdo hipotético relativo a la racionalidad de su contenido, ni mediante una coherencia entre una serie de valores... ¿cómo se justifica entonces? Resumiremos las respuestas de CoHEN a estas preguntas mediante las siguientes tesis:

1. Comenzando por la pregunta $b$ ), COHEN postula un método intuicionista para dar significado al concepto de justicia. Este método presume que la justicia, como el resto de valores morales, posee un significado objetivo que es: $a$ ) Propio de la justicia y, por tanto, distinto del significado de los demás valores morales. b) Pre-existente, externo e inmodificable mediante nuestras discusiones y acuerdos; el objetivo de nuestras discusiones no es crear o decidir el contenido de la justicia, sino descubrir y dar cuenta del significado objetivo que es previo a éstas, y la tarea propiamente filosófica consiste en descubrir, formular y analizar dicho significado ${ }^{80}$. Mediante su intuicionismo, CoHEN se opone a un método constructivista, para el cual somos los individuos quienes integramos el contenido de lo justo construyendo un procedimiento de justificación en el cual ponemos en orden o coherencia una serie de principios o de valores. Sin embargo, para quienes profesan el intuicionismo, la tarea de los individuos no es de

\footnotetext{
79 COHEN, 2008: 159.

${ }^{80}$ Los principios de justicia no son «cosas que decidamos». CoHEN, 2008: 277.
} 
construcción, sino de descubrimiento o captación del significado pre-existente a sus discusiones: «he llegado a la conclusión de que la justicia es la justicia» ${ }^{81}$.

2. La pregunta sobre el significado de la justicia tiene una respuesta clara y un significado específico distinto al de los demás valores morales: justicia es igualdad ${ }^{82}$. Justicia no tiene que ver con el mayor favor a los más desfavorecidos, ni tampoco con la eficiencia o la optimalidad paretiana ${ }^{83}$. Por tanto, el principio de justicia por excelencia es para COHEN «debemos distribuir los bienes de forma igualitaria».

3. En ocasiones, hacer justicia puede conducirnos a resultados que pueden parecernos no ya insatisfactorios, sino incluso malvados o perversos ${ }^{84}$. Si estos resultados nos parecen rechazables es porque la justicia entra en conflicto con otros valores morales, y es desde dichos valores en conflicto con la justicia desde donde formulamos estos juicios de censura hacia resultados meramente justos. El intuicionismo conduce así a una visión pluralista y conflictualista del mundo moral: nuestra experiencia moral nos sitúa muchas veces ante dilemas o alternativas de conducta que conducen necesariamente a la violación o al menoscabo de lo que reconocemos como un valor moral. No hay armonía alguna entre nuestros valores morales, ni algo que pueda ser reconocido como un «orden de valores». Finalmente, no existen reglas objetivas y generales que permitan poner en orden o jerarquizar los valores. Los conflictos morales se resuelven caso por caso, estimando en cada problema particular cuál es el peso que ejerce cada valor en el problema específico, y aplicando el valor que, a nuestro juicio, ostenta un peso superior al de los demás valores en competencia ${ }^{85}$. Del examen de los casos particulares podemos obtener algunas reglas de prioridad de carácter provisional; sin embargo, estas reglas pueden ser corregidas en cuanto se nos presente un nuevo caso tal vez muy similar en apariencia a los que contemplaba dicha regla, pero que exhibe una circunstancia particular añadida que nos mueve a aplicar un principio o un valor distinto ${ }^{86}$. Es la negación de un sistema de reglas generales de prioridad —es decir, de un orden de valores- lo que convierte los dilemas en verdaderos conflictos que no pueden ser disueltos. De contar con una regla precisa según la cual, por ejemplo, la libertad de información tiene prioridad sobre el derecho al honor, el periodista que delibera entre publicar una información comprometedora sobre la vida de un político o no hacerlo sabría que el conflicto en el que se debate es en el fondo aparente, porque, una vez examinada la situación, concluiría que el problema está regido únicamente por la libertad de información; para los intuicionistas, sin embargo, no hay reglas de ordenación objetivas, de modo que los problemas de comportamiento moral, como los de este ejemplo, reproducen verdaderos conflictos, choques de valores en los que, sea cual sea el curso de acción que decidamos, tendremos que reconocer que hemos

${ }_{81}$ Ibid., 155.

82 Ibid., 3.

83 Ibid., 317.

84 «Mean and spiteful», Ibid., 318.

85 «No todos los valores pueden ser siempre satisfechos, y no hay forma de combinar todos ellos sistemáticamente». Ibid., 4. La idea era ya claramente expresada en los clásicos del intuicionismo moral: Ross, 1955: 24. «Para la estimación comparativa de las obligaciones prima facie no podemos contar con el establecimiento de reglas generales». Ibid., 41. «Pensamos, después de considerar debidamente cada caso, que un deber tiene más peso que el otro, pero no sentimos certeza alguna al respecto». Ibid., 21-22.

${ }_{86}$ En la concepción intuicionista «los juicios individuales mantienen una cierta soberanía». COHEN, 2008: 4. 
vulnerado alguno de los valores morales reconocidos, y que se ha consumado una pérdida moral ${ }^{87}$.

El valor de la justicia no escapa a esta descripción del mundo moral. Si el juicio «(10,6) es menos justo que $(5,5) »$ nos parece insensato es porque este juicio se limita a aplicar el valor de la justicia, porque el valor de la justicia entra en conflicto con otros valores, y porque juzgamos que dichos valores ostentan en el caso un mayor peso que la justicia. De hecho, son frecuentes los conflictos entre la justicia y otros valores como la eficiencia o la optimalidad paretiana, el bienestar general, la publicidad, la estabilidad, etcétera ${ }^{88}$.

Si no hay orden de valores ni reglas de prioridad objetivas en el mundo moral, no podemos atribuir a la justicia ninguna presunción de prioridad con respecto a los demás valores. No es cierto que la justicia sea generalmente, como afirma RAWLS, la primera virtud de las instituciones sociales, como tampoco lo es en la vida privada ${ }^{89}$. Según las circunstancias de cada caso, puede ser derrotada por otros valores que ejerzan un mayor peso.

4. La teoría moral debe distinguir cuidadosamente entre «principios» $\mathrm{y}$ «reglas de regulación».

Los principios son elaborados singularmente por la filosofía en su tarea de elucidación de los valores morales. Esta formulación es inmune o insensible al mundo fáctico ${ }^{90}$ : si sabemos, sentimos o pensamos ${ }^{91}$ que la justicia es esencialmente igualdad, sería una contradicción flagrante corregir este juicio en función de las consecuencias empíricas coyunturales que acarreara una distribución igualitaria específica. Los principios de justicia son normativos y se sustentan sobre una base puramente normativa. Es posible que, en ocasiones, hallemos algún principio moral que parezca perfilado o recortado en virtud de una serie de circunstancias fácticas. Pero, en ese caso, lo que sucede es que dicho principio no es un principio independiente, sino la conclusión de otro principio más abstracto, principio que ya podemos considerar como principio moral en sentido estricto, y que se distingue por no derivar su enunciado de ninguna consideración fáctica ${ }^{92}$.

El constructivismo en general, y el de RAWLS en particular, justifican sus principios de justicia en función de una serie de hechos, en concreto una serie de circunstancias relativas a los individuos y a las sociedades ${ }^{93}$. No es así extraño que el principio de diferencia, con el que RAWLS reformula el significado de la justicia distributiva, sea presentado como un principio dependiente de una serie de condiciones fácticas, como el hecho de que algunos individuos disfrutan de más cualidades físicas e intelectuales que otros, y aportan así un mayor capital social.

87 AUDI, 1996: Section «Traditional Ethical Intuitionism», 102 y ss.

88 COHEN, 2008: 4, 285 y ss.

89 Ibid., 302 y ss. Por supuesto, se trata de una impugnación radical del comienzo de la sección 1 de $A$ Theory of Justice. RaWLS, 1971: 3.

90 CoHEn, 2008: 238. Los principios éticos «deben ser comprobados atendiendo al menor número posible de hechos generales que sepamos implicados en el caso». PRICHARD, 1968: ix.

91 El intuicionismo de COHEN «no está comprometido con epistemología alguna que identifique alguna facultad encargada de la percepción moral». COHEN, 2008: 4.

92 Ibid., 229.

93 Ibid., 275. 
En realidad, las normas morales cuyo ámbito de validez está confeccionado con arreglo a condiciones fácticas no son principios, sino «reglas de regulación». La formulación de estas reglas no representa ya un asunto puramente filosófico: dado que ahora entran en escena consideraciones fácticas que deberán ser analizadas, las consideraciones filosóficas habrán de combinarse con análisis sociológicos, económicos, históricos, etc. ${ }^{94}$. Si los principios son normas que descubrimos y formulamos desde el análisis filosófico, las reglas son normas que «adoptamos o creamos» en función de que los resultados de su imposición, calculados de acuerdo con las circunstancias del caso, nos satisfagan más o menos ${ }^{95}$. Por último, las reglas de regulación sirven para resolver provisionalmente los conflictos entre valores morales. La solución a los conflictos de valores sí depende de circunstancias fácticas contingentes, y por eso se obtiene mediante reglas de regulación ${ }^{96}$. De este modo, el juicio « $(10,6)$ es una distribución moralmente superior a $(5,5) »$ establece una regla de regulación provisional que atribuye un mayor peso a valores como la eficiencia o el bienestar que a la justicia.

Las tesis anteriores reinterpretan de un modo sorprendente los puntos de vista que CoHen había adoptado inicialmente sobre la teoría de RAwLs. Después de un largo viaje destinado a oponerse y distanciarse de esta teoría, al final COHEN no niega que los puntos de vista de RAWLS pueden ser correctos, pero siempre y cuando su teoría sea interpretada no como una teoría de la justicia destinada a justificar una serie de principios de justicia, sino como un conjunto de reglas de regulación social de carácter provisional y justificadas en el contexto de una serie de circunstancias contingentes ${ }^{97}$. En los años noventa, en el contexto del discurso esbozado en el epígrafe 2, era frecuente hallar en su obra acusaciones contra RAWLS que denunciaban la sumisión de su teoría de la justicia a meros hechos (el mayor número de células grises de los más talentosos, el egoísmo propio del individuo modelado por el capitalismo, etc.). En sus últimos escritos, deja abierta la posibilidad de que, en ocasiones, pueda ser moralmente preferible atribuir más rentas y riquezas a los más talentosos para, de acuerdo con el principio de diferencia, otorgar una mayor dotación de bienes a los más desfavorecidos. La novedad es que ahora no podemos llamar al principio de diferencia «principio», sino «regla de regulación»; tampoco podemos denominarlo «principio de justicia», porque lo justo consiste en la igualdad estricta; por último, tampoco podemos establecer su corrección de una forma general y categórica, sino sólo dentro de un determinado abanico de circunstancias que pueden variar en cualquier momento. En suma, el principio de diferencia es una regla de regulación que puede en ocasiones ser la regla moralmente preferible, si bien, inevitablemente, tolerando ciertas injusticias.

También puede resultar desconcertante comprobar que toda la carga crítica que atesoraba la teoría de COHEN frente al abuso de los incentivos o el afianzamiento de

94 «La pregunta... "¿qué reglas de regulación deben gobernar las sociedades"... depende fuertemente de hechos sociales generales. La pregunta "¿qué es justicia?” es una cuestión filosófica» que ya no depende de hechos generales. COHEN, 2008: 277.

${ }^{95}$ COHEN, 2008: 276.

96 «Otros principios... entran en conflicto con la justicia... y los hechos nos ayudan a decidir el peso o la lealtad que hemos de prestar a cada uno de ellos». COHEN, 2008: 272. Para Ross, resolver los conflictos dependía de examinar qué hecho o qué circunstancia era la más relevante en el problema. Ross, 1955: 19.

97 CoHen, 2008: 269. Como concluye irónicamente Pogge (2009: 90), cualquier nueva edición del clásico de RAWLS deberá corregir su título y denominarse $A$ Theory of Social Regulation o «Una teoría de la regulación social». 
la desigualdad queda en buena medida desactivada y diluida dentro de su concepción metaética. Los privilegios y las desigualdades son seguramente injustos, pero puede que sean moralmente preferibles: la justicia no es la primera virtud de las instituciones sociales, de modo que nuestras inclinaciones igualitarias pueden verse desplazadas por otros valores, sin que existan reglas de prioridad objetivas que atribuyan ventaja a la igualdad frente al resto de principios. Tal vez podamos tener la impresión de que CoHEN ponderaría en favor de la igualdad o de la justicia muchas más veces de las que lo harían otros, especialmente en problemas económicos y sociales como los que hoy nos afectan. Pero no podemos saberlo con certeza ${ }^{98}$.

Más relevante es subrayar que estos cambios se han operado bajo el impulso de una metaética intuicionista y, como el mismo COHEN insiste en denominar, platónica. El asalto final de COHEN a la teoría de RAWLS trata de arrancar las raíces más profundas de su concepción, en especial el método constructivista que RAWLS hace explícito desde $1980^{99}$, según el cual nuestros desacuerdos sobre lo justo revelan que no podemos confiar en ningún significado pre-existente del valor de la justicia, y que hemos de resolver el problema mediante un procedimiento de argumentación y consenso en el que establezcamos un orden o coherencia entre nuestras principales intuiciones normativas sobre el problema y los resultados que vayamos alcanzando en nuestro procedimiento ${ }^{100}$. Frente a ello, CoHEN abraza una metaética desusada y comprometedora que le conduce a problemas de difícil solución. Sin posibilidad de exponerlos en profundidad, me limitaré a presentar brevemente algunos de ellos.

A diferencia del resto, la primera consideración mostrará un cierto acuerdo con una de las tesis de COHEN, en concreto la que sostiene que el contenido de nuestros principios de justicia no deriva de circunstancias fácticas. En realidad, podemos incluso ser más ambiciosos: si la expresión «derivar de circunstancias fácticas» quiere decir que el ámbito de validez de las normas está recortado o perfilado por dichas circunstancias de una forma decisiva, en ese caso podemos extender esta tesis a las reglas de regulación. El ámbito de validez de las reglas de regulación no está recortado o perfilado mediante hechos; si un hecho nos inclina a modificar o excepcionar una regla, ello se debe a que este hecho nos parece relevante o salient en el caso particular; pero, en ese caso, el verdadero papel de esta circunstancia es el de servir de vehículo de descubrimiento de otros principios o valoraciones morales que, de otro modo, nos habrían pasado inadvertidos. Por recurrir al conocido ejemplo de SCHAUER ${ }^{101}$, si adoptamos la regla «prohibida la entrada de animales en nuestro restaurante», pero hoy permitimos la entrada de un perro lazarillo, afirmar simplemente que «hemos corregido la regla porque uno de los clientes era ciego» no es una descripción adecuada del razonamien-

98 El carácter monista de su teoría de la justicia deja el valor de la justicia en una situación aún más precaria. Es evidente que en el ámbito privado, donde las relaciones personales y la preservación de las relaciones comunitarias o asociativas es esencial, la justicia o la igualdad ostenta un peso menos elevado que en el ámbito público cuando la comparamos con otro tipo de virtudes como la lealtad, la fidelidad o los deberes de obediencia al grupo.

99 En «Kantian Constructivism in Moral Theory», RAWLS, 1980: 515-572.

$100 \mathrm{O}$, según sus términos, cuando alcancemos un «equilibrio reflexivo». RaWLS, 1971: 20. Presumiré sin detenerme en demostrarlo que este procedimiento de justificación es una estrategia coherentista. Vid., por ejemplo, O’NEILL, 2002: 351-352.

101 SCHAUER, 2006: 45 y ss. 
to moral que hemos desarrollado: la entrada de un cliente ciego nos ha revelado una circunstancia relevante que nos había pasado inadvertida, pero esta circunstancia es relevante porque nos ha conducido a una serie de principios o de valoraciones normativas que no habíamos introducido a la hora de formular nuestra regla, en concreto el trato diferencial moralmente justificado en casos de discapacidad. Distinguir entre «principios» $\mathrm{y}$ «reglas» atendiendo a este supuesto fenómeno es, por tanto, elegir un criterio de distinción equivocado.

Es posible estar de acuerdo con COHEN en que el significado de los principios no deriva de circunstancias fácticas. Sin embargo, es erróneo afirmar que RAWLS infringe esta premisa. No creo que un principio de justicia como el principio de diferencia infiera su enunciado de imposiciones fácticas, algunas de los cuales son especificadas por COHEN como «enfermedades morales humanas» ${ }^{102}$. Como ya describimos en el epígrafe 2, COHEN acusa a RAWLS de presumir una concepción del individuo que lo identifica con el homo oeconomicus propio de la microeconomía clásica, así como una determinada idea de la sociedad que está regida por el sistema de producción capitalista. Según él, RAWLS reconocería estas dependencias desde el comienzo de su exposición, cuando explica que su teoría se cimenta sobre una serie de concepciones teóricas sobre el individuo y sobre la sociedad. La conclusión de un procedimiento construido de este modo es un llamado «principio» de diferencia que es en realidad una regla de regulación en la cual, infiriendo a partir de los hechos generales de la psicología humana proporcionados por estas concepciones (es decir, teniendo en cuenta el egoísmo del individuo capitalista) ${ }^{103}$, concluimos que lo más justo para todos es que el mayor mérito de los más talentosos sea debidamente recompensado. Sin embargo, es un error afirmar que el procedimiento de RAWLS se instruye y se modela bajo la imposición de una serie de circunstancias fácticas, o que la coherencia final se limita a formular los principios que casen con estas circunstancias. Las concepciones del ciudadano y de la sociedad que RAWLS introduce en el procedimiento no son un mero catálogo de condicionamientos fácticos, sino una serie de concepciones teóricas normativas que son seleccionadas a partir de un conjunto de juicios morales considerados, de creencias morales intuitivas fuertemente afianzadas en nuestras sociedades, y que representan el modo de vernos a nosotros mismos y a nuestras sociedades. Cuando RAWLS explica que el velo de la ignorancia se sustenta en una concepción de los individuos en la cual éstos son libres de forma que pueden distanciarse de su propia concepción del bien, no formula esta idea porque se sienta obligado a hacerlo ante la exactitud de una determinada explicación científica, sino porque ésta es la forma de vernos a nosotros mismos que mejor casa con nuestras convicciones morales intuitivas más arraigadas ${ }^{104}$. Por lo demás, las concepciones teóricas del procedimiento rawlsiano tampoco disfrutan del carácter definitivo que atribuimos a las aserciones científicas: caso de que estas

102 COHEN, 2008: 309.

103 COHEN (2008: 330) subraya un pasaje de RAWLs (1971: 455) en el que éste llama la atención sobre la necesidad de que la teoría case con los hechos generales de la psicología humana, y pueda ser atractiva para los individuos, es decir, genere el deseo de actuar de acuerdo con sus conclusiones.

104 RAWLS dice inspirarse en las «ideas más familiares» que suministra «la cultura de una sociedad democrática» o «las tradiciones de interpretación de su constitución y de su derecho fundamental». «Presumo que los ciudadanos de una sociedad democrática tienen, cuando menos, una comprensión implícita de estas ideas tal y como se manifiestan en la discusión política diaria, en los debates sobre el significado y el fundamento de los derechos y libertades básicos y en escenarios similares». RAWLS, 2001: 5 . 
concepciones y el constructo resultante de la posición original nos hubieran conducido a principios que nos resultaran contraintuitivos, la falta de coherencia nos movería a pensar que hemos cometido algún error, a desconfiar de nuestros juicios considerados y a reformar o modificar las construcciones teóricas seleccionadas ${ }^{105}$. En última instancia, lo que justifica los principios es la coherencia final alcanzada entre todos los elementos introducidos en el procedimiento. No es cierto así que el constructivismo se limite a dar cuenta de las preferencias morales de cada filósofo presentándolas como una necesidad fáctica; el principio de diferencia pone en orden una serie de intuiciones, principios y valoraciones normativas, y no es correcto afirmar que su contenido es perfilado o es recortado obedeciendo imperativos fácticos ${ }^{106}$.

Por supuesto, el problema fundamental de la metaética de COHEN es la imposibilidad de justificar debidamente el significado de los valores morales, así como sus rasgos de conflictividad y pluralidad. El intuicionismo confía en el descubrimiento de una serie de cualidades morales objetivas que presentan la misma evidencia que las cualidades naturales. Pero, en general, los intuicionistas reconocen que no tenemos un acceso directo o por medio de los sentidos a dichas cualidades, de modo que sólo la intuición nos permitirá el conocimiento de las mismas ${ }^{107}$. COHEN sitúa el origen de estas intuiciones morales en el examen de casos particulares: el análisis de estos casos nos hace emitir una serie de juicios morales intuitivos que funcionan como aprehensiones inmediatas de la naturaleza y del significado de los valores morales; finalmente, de la generalización de estos juicios resultará la formulación de una serie de principios generales ${ }^{108}$. Como sabemos, las intuiciones sobre la justicia convergen, para COHEN,

105 Por eso afirma que no debemos interpretar estos argumentos «como una base», en el sentido fundacionalista de un pilar inamovible, origen de todas las inferencias. «Todo depende de cómo se organice la exposición como un todo». RAWLS, 2001: 5, n. 5

106 He discutido una forma de interpretar la expresión «principios que se derivan de hechos» en la cual el contenido de las normas se deriva de una serie de circunstancias fácticas. He expresado mi acuerdo con COHEN a la hora de criticar esta derivación. Sin embargo, existe otra interpretación posible en la cual los hechos se limitan a constituir el ámbito de problemas al que se orientan nuestras discusiones: el problema de la organización de las sociedades, el problema de la obra artística... Sin tiempo para una larga discusión al respecto, creo que esta segunda forma de interpretar la sensibilidad hacia los hechos de nuestras preferencias normativas no es ya denunciable ni siquiera desde el platonismo de COHEN: afirmar que un principio P1 resuelve el problema del juicio artístico mientras que otro P2 no lo hace, porque habla de justicia, no merece la crítica de sumisión a los hechos. En el mismo sentido: BuCKLEY, 2010: 398-399. Si no interpreto mal a PogGE, es lo que éste denominaría la «sensibilidad externa» de los principios hacia los hechos, frente a la sensibilidad interna a la que nos hemos referido en el texto. Vid. PoGge, 2009: 93 y ss. Le agradezco a T. PoGgE sus aclaraciones a mis preguntas sobre esta cuestión.

107 «No tenemos un medio de acceder directamente a los hechos que distinguen lo bueno y lo recto, de modo que la forma de acceder a qué cosas son buenas o rectas es pensando sobre ellas: las convicciones morales de las personas cultas y juiciosas son los datos de los que parte la ética, de igual forma a como las percepciones sensitivas son los datos de los que parten las ciencias naturales». Ross, 1955: 40-41.

108 COHEN, 2008: 4. Para los intuicionistas clásicos, esta aprehensión de valores ostenta el carácter de auto-evidente, razón por la cual las intuiciones tienen en todo momento prioridad con respecto a los principios. PRICHARD, 1968: 8. COHEN no habla de auto-evidencia, pero sí de «cierta soberanía» de las intuiciones con respecto a los principios, lo que respalda la prioridad de aquéllas. Esta prioridad de las intuiciones relativas a casos particulares no se verifica en el constructivismo ralwsiano. Es cierto que, como se ha dicho, RAwLS procede a partir de una serie de concepciones que resultan de juicios morales intuitivos formulados en circunstancias apropiadas. Sin embargo, los principios resultantes de su teoría pueden enmendar después las intuiciones de partida, y proporcionar reglas de prioridad que resuelvan los supuestos conflictos o choques de intuiciones. Así, RAWLS emplea algunas secciones de A Theory of Justice en demostrar que el conocimiento sobre la justicia que nos proporciona nuestro sentido común es insuficiente, y nos conduce a errores que su teoría permite co- 
en un principio fundamental de igualdad. COHEN procede en todo momento como si, dentro de un contexto moral de libertad y responsabilidad humanas, ningún juicio moral intuitivo sobre caso particular alguno amenazara nunca la evidencia de que la distribución más justa es la más igualitaria; allí donde nuestro examen del caso parece matizar o incluso desplazar la igualdad, allí nos hallamos bajo la influencia de otro principio moral distinto a la justicia, principio que entra en conflicto con ésta y que puede llegar a derrotarla. Por supuesto, podemos presumir que COHEN no es inconsciente de que no son pocos los filósofos que han desafiado la relación necesaria entre justicia e igualdad, y han abogado por rescatar la idea romana de que la justicia es, simplemente, «dar a cada uno lo que es suyo». La respuesta de COHEN a quien elude identificar justicia con igualdad es que, desde que eluden este significado, están hablando de otra cosa. Sin embargo, es obvio que estos autores hacen algo diferente a hablar de otra cosa: están socavando los argumentos de COHEN, porque están afirmando que sus intuiciones sobre lo que es justo o sus juicios morales particulares les conducen a vincular el valor de la justicia con significados distintos a los que formula COHEN ${ }^{109}$. Este enfrentamiento entre intuiciones morales conduce a la conclusión de que lo que se presenta como una mera descripción de cualidades y de significados evidentes es en realidad una adscripción o una atribución arbitraria ${ }^{110}$.

La aprehensión intuitiva y platónica de cualidades morales le conduce a COHEN a observar los hechos morales como entidades en permanente conflicto: cada caso particular suele ser el escenario de un choque entre una pluralidad de valores, y, una vez más, sólo el examen de cada caso y el uso de nuestras intuiciones morales podrán calibrar el peso de cada valor y determinar cuál de ellos permite resolver el caso. Sin embargo, esta descripción de un mundo objetivo de cualidades y hechos morales se ajusta muy difícilmente a nuestras prácticas morales. Aunque éste no es lugar adecuado para un examen en profundidad de estos problemas, sí podrá apreciarse que esta imagen conflictualista, tal y como COHEN la ha presentado, introduce algunas anomalías en nuestra comprensión del mundo moral. Por lo pronto, puede observarse que el modelo intuicionista renuncia a la posibilidad de otorgar una justificación objetiva a las prioridades que resuelven los conflictos de valores: el conflicto no puede resolverse mediante reglas de prioridad objetivas y generales porque nuestros valores no conforman sistema alguno, de modo que el siguiente caso puede excepcionar la regla. Es posible que, para algunos, esta respuesta sea suficiente para eludir el problema de justificación que denunciamos, pero creo que conduce a otro. COHEN insiste en afirmar que su metaética es perfectamente neutral, porque no prejuzga ni determina el signi-

rregir. RAWLS, 1971: sección 47, 304 y ss. En el intuicionismo, las intuiciones o los juicios particulares corrigen los principios, pero no a la inversa; en el constructivismo de RAWLS, existen intuiciones y principios, pero la posibilidad de corrección es de doble sentido.

109 Los casos de NOZICK o HAYEK son bien conocidos. Vid. una fuerte crítica a este punto en ARNESON, 2009: 12 .

${ }_{110}$ CoHen rechaza la identificación de su metaética con un punto de vista fundacionalista de la justificación, y ello porque en ningún momento afirma que sus principios sean auto-evidentes. Sin embargo, su vinculación entre justicia e igualdad descansa en una serie de intuiciones que gozan de una especie de «soberanía». Para SAYRE-MCCORD (1996: 149), el fundacionalista se distingue por pensar «que hay una clase privilegiada de creencias que no están inferencialmente justificadas, y sin las cuales el resto de creencias carece de justificación». Desde esta definición, COHEN no escapa del fundacionalismo ni de sus problemas de teoría de la justificación. 
ficado o el contenido de nuestras creencias morales, y que podría ser aceptada por un conjunto muy vasto y heterogéneo de concepciones ${ }^{111}$. Sin embargo, hablar aquí de neutralidad en lo substantivo es dudoso: ante un determinado conflicto moral, aquel que esgrimiera una supuesta regla de prioridad general a favor de un determinado valor sería de inmediato acallado por los seguidores de COHEN, que no creen posible la existencia de dichas reglas, ni se introducirían en debate alguno sobre las mismas. Este veto a un tipo de argumentos podría favorecer un determinado resultado, y perjudicar a otro, de modo que la prometida neutralidad es en realidad inexistente.

Un tercer problema puede ser identificado en el carácter prima facie que COHEN atribuye a los principios morales. Desde su punto de vista, un caso particular suele enfrentar a distintos principios morales (de justicia, eficiencia, etc.) que son válidos y obligatorios en dicho caso concreto; el problema moral consiste en determinar cuál de estos principios ejerce un mayor peso o influencia en el caso; una vez realizada esta operación, aplicamos el principio ganador, y nos resignamos a una situación de pérdida moral, porque admitimos que otro principio, o incluso una serie de principios morales válidos y obligatorios van a ser desobedecidos en un determinado caso ${ }^{112}$. Sin embargo, ésta es sólo una forma de interpretar qué queremos decir cuando afirmamos que un determinado deber es prima facie. De acuerdo con la terminología de D. O. BRINK, COHEN suscribe una interpretación o una concepción «metafísica» de los deberes prima facie. Una concepción distinta es la concepción «epistémica» ${ }^{113}$. En ella, admitimos que los problemas particulares parecen enfrentar a distintos principios morales que parecen válidos y obligatorios en el caso particular, por lo cual los entendemos como principios aplicables prima facie en dicho caso particular. Sin embargo, entendemos que la validez y obligatoriedad en el caso de todos los principios convocados es sólo una hipótesis teórica a primera vista verosímil, pero que hemos de confirmar después en el análisis del problema. Este análisis no consiste en una ponderación de los pesos o escalas de cada principio, sino en la determinación de cuál o cuáles de estos principios rigen verdaderamente el caso, cuál o cuáles son válidos y obligatorios con exclusión de los demás, y cuales otros, pese a que haya circunstancias que a priori nos inclinaran a considerarlos como posibles principios válidos, en realidad no son los principios válidos y obligatorios del caso, y han de ser excluidos a la hora de solucionarlo. En suma, un principio prima facie es una hipótesis, una presunción o una razón a priori de que debemos hacer algo; cuestión distinta es afirmar que no sólo son razones, sino también «buenas» razones, o que imponen deberes u obligaciones morales: el examen del caso revelará, una vez consideradas todas las razones, que éste se incluye en el ámbito de validez de uno de los principios en disputa, con exclusión de los demás ${ }^{114}$.

111 COHEN, 2008: 257.

112 Las obligaciones morales no son erradicables, y permanecen aun después de que se ponderen los principios y se resuelva el conflicto. Tampoco es erradicable la sensación de pérdida moral, y los sentimientos de remordimiento y pesar juzgados como moralmente apropiados: «Sostengo que el remordimiento es moralmente apropiado cada vez que una obligación prima facie ha sido violada, con independencia de que fuese moralmente permisible violarla». PIETROSKI, 1993: 509.

113 BRINK, 1996.

114 DWORKIN lo resume muy expresivamente: «Nuestra situación es muy diferente de la de Abraham: no estamos sujetos a dos poderes soberanos, uno de los cuales nos ordena libertad de expresión y el otro persecución de los insultos racistas. Por el contrario, estamos relacionados con cada una de las posiciones rivales por argumentos que, de ser finalmente aceptados como vinculantes, nos liberarían del atractivo que sentimos 
Creo que el error de COHEN en la descripción de nuestras prácticas morales puede resumirse en la preferencia errónea e injustificada por una interpretación metafísica de lo que significan los principios prima facie. Por continuar con el ejemplo del perro lazarillo, parece muy claro que el invidente tiene el mismo derecho a entrar en el restaurante que el plenamente capacitado, y que no tiene por qué sentirse responsable de «pérdida moral» alguna. Creo que pueden esbozarse dos posibles fuentes de este error de COHEN. La primera es presumir de partida y antes de analizar el caso la solución al problema que está en disputa: cuál de los principios que parecen coincidir en el caso es el obligatorio y debe, por tanto, regir mi conducta. Los partidarios de la concepción metafísica se apresuran a afirmar que lo son todos sin que haya razones concluyentes para afirmarlo; es cierto que hay hechos que inclinan a pensar que un determinado principio $\mathrm{P}$ puede ser obligatorio, pero de igual forma a como en cualquier problema fáctico hay circunstancias que nos inclinan a pensar en varias causas, y sólo después de comprobarlas todas descartamos las que no han producido efecto alguno. Afirmar a priori que el caso está regido por todos los principios prima facie nos mueve así a reconocer que existen principios obligatorios en el caso, pero finalmente no aplicados, lo que significa el reconocimiento en cada caso de derechos y de expectativas morales que, finalmente, van a verse frustradas. Antes que reconocer paladinamente que incurrimos en contradicciones tan flagrantes cada vez que nos enfrentamos con un caso particular, ¿no es una reacción más verosímil en cualquier agente moral el esfuerzo por formular de forma previa y general en qué casos nuestros principios reconocen derechos o imponen obligaciones y en qué casos no?

La segunda fuente de error es la atribución a los principios de un ámbito de validez casi universal y, desde luego, no delimitable o especificable mediante una serie de reglas generales ${ }^{115}$. El principio fundamental de justicia «lo justo es distribuir los bienes a partes iguales» es aplicable siempre que se realice una distribución entre varios individuos libres y responsables. Ahora bien, según COHEN, este principio será válido y obligatorio en cualquier problema distributivo, lo que conduce a establecerlo como principio válido para las instituciones públicas, pero también para comunidades y asociaciones privadas, tales como la empresa o la familia, y probablemente para la distribución no sólo de rentas y riquezas, sino de otros bienes primarios como el respeto. Como se ha denunciado, de este monismo estricto podrían inferirse conclusiones absurdas, como el deber del padre o del amigo de querer en igual medida a todos los miembros de su familia o su pandilla de amigos. COHEN eludiría esta conclusión al interpretar estos ejemplos como conflictos entre principios en los que, finalmente, la justicia es desplazada por otros principios de mayor peso; sin embargo, no puede elu-

por el otro». DwORKIN, 2006: 111. Para SCANLON (1998: 56-57): los principios prima facie son razones, pero tener una razón es un hecho, no una obligación; para que se transformen en obligaciones, las razones han de acreditarse como «buenas» razones. Para HeRman, en los conflictos morales no se trata de justificar qué obligación prevalece, como si hubiera más de una; los principios prima facie proporcionan lo que KANT denominaba «fundamentos de obligación»; pero éstos fundamentos ni siquiera podían llamarse «razones», sino meras presunciones de racionalidad práctica. HeRMAN (1993: 168).

115 A PogGe (1996: 95) también le llama la atención que sus principios son «sensibles a los hechos en sentido externo», es decir, están vagamente determinados en lo que se refiere a qué tipo de problemas dirimen. Sin embargo, no son «sensibles en sentido interno», porque no sabemos cuándo se aplican realmente y cuándo son derrotados por otros principios, lo que, según POGGE, desencadena la conclusión de que COHEN no rescata ni la justicia ni valor alguno. 
dir otras consecuencias igualmente absurdas: que el principio de justicia es obligatorio en estos casos, y, si esto es cierto, que el deber de querer a amigos y parientes por igual es obligatorio, aunque se vea finalmente superado por otros, en cuyo caso hemos de reconocer una situación de pérdida moral ${ }^{116}$. Mucho más sensata es la concepción según la cual los principios, tomados aisladamente, son normas cuyo ámbito de validez es indeterminado ${ }^{117}$. Para establecer su ámbito de validez, necesitamos reglas que integren el conjunto de casos en el que son necesariamente aplicables y obligatorios, perfilen su ámbito de validez y lo distingan del ámbito de validez de otros principios. Esta tarea de delimitación y de separación del ámbito de validez de los principios equivale a la tarea de ponerlos en orden o en coherencia. De este modo, el significado preciso o el ámbito de validez de cada principio se determinan mediante el concurso de todos los demás principios, porque esta tarea de determinación exige incluir el principio que definimos dentro de un sistema, de una teoría que imponga coherencia a nuestros principios. Como repite BRANDOM, necesitamos muchos conceptos para explicar el significado de uno solo ${ }^{118}$, y necesitamos poner en orden una pluralidad de principios y de valores morales para perfilar el significado o el ámbito de validez de la justicia. Limitarnos a decir que justicia es esencialmente igualdad supone así un problema práctico, porque, $a$ priori, no sabemos en qué casos particulares debemos imponer igualdad y en qué casos no; es también un problema de conocimiento: si sólo contamos con la idea de que justicia es igualdad, aún no sabemos en qué casos debemos aplicar este principio; y, si no sabemos en qué casos debemos aplicar el principio, no conocemos de forma adecuada el sentido o el significado del valor de la justicia ${ }^{119}$. Para alcanzar este conocimiento precisamos de una teoría, de una concepción de la justicia, y ésta sólo puede obtenerse poniendo en orden el ámbito de validez de los principios más importantes que gravitan en torno al problema de la justicia, y ordenándolos en torno a un sistema coherente. Y ésta es la tarea que realiza J. RAWLS. En realidad, sus llamados principios de justicia son una serie de reglas generales que permiten perfilar y delimitar el sentido que debemos atribuir al valor de la justicia. Pero este significado ha sido formulando después de poner en orden o en equilibrio una larga lista de valores, de principios y de expectativas morales. Particularmente, el principio de diferencia es una regla que permite integrar el sentido de la justicia distributiva, pero que es a su vez una ordenación de distintos valores, principios y expectativas, como son la igualdad, la eficiencia, etcétera ${ }^{120}$.

116 Si hacemos equivaler justicia y una interpretación estricta del principio de diferencia, habríamos de justificar un deber de mayor respeto y amistad hacia los más desfavorecidos. POGGE, 2000: 161.

117 Las reglas configuran de forma «cerrada» su ámbito de validez; los principios de forma abierta. ATIENZA-RUIZ MANERO, 1996: 9. «Los principios prácticos son vagos» y carecen de legalistic precision». HARMAN, 1978: 111, cursivas mías.

118 BRANDOM, 1994: 89.

119 Por acudir al ejemplo de SCANLON (1998: 100), si empleamos la música de los últimos cuartetos de Beethoven como música de ascensor de nuestra empresa, el error no es haber puntuado y priorizado erróneamente música y negocios: el problema es entender mal el valor de la música.

120 Por eso también la justicia es concretada dentro del ámbito de las instituciones fundamentales de la estructura básica de la sociedad. Eso no quiere decir que, para RAWLS, el ámbito privado sea un espacio vacío de justicia. Como se ha dicho, no es tarea de este ensayo discutir el dualismo de RAWLs frente al monismo de COHEN. Bastará con observar un hecho reconocido por los monistas: la enorme influencia que un derecho justo (por ejemplo un derecho de familia o un derecho laboral) puede ejercer sobre las asociaciones privadas. Un monista como MURPHY no duda en afirmar que «si las instituciones de la estructura básica hacen su trabajo debidamente, es poco lo que los individuos tendrán que pensar acerca de, [por ejemplo], cómo promover el bienestar general». MURPHY, 1998: 15. 
En realidad, el principio fundamental de justicia de COHEN es válido y obligatorio de forma casi universal, pero no hay razón ni regla general a priori para negar la idea de que, tal vez, podría no ser aplicable nunca, porque podría ocurrir que los casos particulares convocaran siempre a principios de mayor peso. Como se ha dicho, CoHEN termina privando a su teoría de la justicia de todo vigor crítico frente a las desigualdades reales. Frente a lectores perplejos, COHEN opone la idea platónica de que la tarea de la filosofía no es la legislación ni la práctica política, sino el conocimiento puro: la captación de valores supone la formulación de un significado; ésta es una tarea puramente teórica y, con ello, la tarea propiamente filosófica, mientras que la utilización de estos valores en la práctica y la resolución de sus conflictos es ya una tarea política y legislativa ${ }^{121}$. La pregunta que cabe formularse entonces es qué queda en COHEN del marxismo, sobre todo si consideramos que, puestos a desentrañar el contenido esencial del marxismo, una de las tesis menos polémicas es la que atribuye a la filosofía como misión fundamental no el conocimiento puro, sino la transformación de la realidad ${ }^{122}$.

\section{BIBLIOGRAFÍA}

ARnESON, R. J., 2009: «Justice is not Equality», en B. FelthAm (ed.), Justice, Equality and Constructivism, Chichester: Wiley-Blackwell.

Atienza, M., y Ruiz Manero, J., 1996: Las piezas del derecho, Barcelona: Ariel.

Audi, R., 2002: «Intuitionism, Pluralism and the Foundation of Ethics», en W. SinNOTT-ARMSTRONG (ed.), Moral Knowledge?, New York: Oxford U. P.

Brandom, R., 1994: Making it Explicit, Cambridge (Mass.): Harvard U. P.

BRINK, D. O., 1996: «Moral Conflict and Its Structure», en H. E. MasOn (ed.), Moral Dilemmas and Moral Theory, New York: Oxford U. P.

BuCKLEY, M., 2010: «Review of “Rescuing Justice \& Equality” », Journal of Value Inquiry, 44.

CARENS, J., 1981: Equality, Moral Incentive and the Market, Chicago: U. P.

Cohen, G. A., 1978: Karl Marx's Theory of History: A Defence, Oxford: U. P.

- 1995: Self-Ownership, Freedom and Equality, Cambridge: U. P.

- 2008: Rescuing Justice and Equality, Cambridge: Harvard U. P.

Cohen, J., 2002: «Taking People as They Are?», Philosopby E Public Affairs, 30.

DwOrkIn, R., 1978: Taking Rights Seriously, Cambridge: Harvard U. P.

- 2000: Sovereign Virtue, Cambridge: Harvard U. P.

- 2006: Justice in Robes, Cambridge: Harvard U. P.

Harman, G., 1978: «Reasons», en J. Raz (ed.), Practical Reasoning, Oxford: Oxford U. P.

Herman, B., 1993: The Practice of Moral Judgment, Cambridge: Harvard U. P.

KymliCKA, W., 1990: Contemporary Political Philosophy, Oxford: Clarendon.

121 COHEN, 2008: 284. En realidad, esta oposición entre el filósofo y el legislador le coloca un peldaño por encima de PLATÓN en lo que a idealismo se refiere. Su esfuerzo por agotar el sentido del valor de la justicia mediante la igualdad y la responsabilidad desencadena proclamaciones no menos contundentes: la justicia no tiene por qué ser pública ni visible, una justicia invisible para todos los hombres sería también justicia, la justicia no tiene por qué garantizar orden estable alguno (COHEN, 2008: 345, 325, 329).

122 Le agradezco al profesor M. Á. RoDiLla la generosidad que ha mostrado leyendo y comentando estas páginas. 
Murphy, L. M., 1998: «Institutions and the Demands of Justice», Philosophy E Public Affairs, 27.

Nozick, R., 1974: Anarchy, State and Utopia, Oxford: Blackwell.

O’NeIll, O., 2002: «Constructivism in Rawls and Kant», en S. FreEman (ed.), The Cambridge Companion to Rawls, Cambridge: Cambridge U. P.

Pietroski, P. M., 1993: «Prima Facie Obligations, Ceteris Paribus Laws in Moral Theory», Ethics, 103.

Pogge, T., 2000: «On the Site of Distributive justice. Reflections on COHEN and Murphy», Philosophy E Public Affairs, 29.

- 2009: «Cohen to the Rescue!», en B. Feltham (ed.), Justice, Equality and Constructivism, cit.

Prichard, H. A, 1968: Moral Obligation, Oxford: Oxford U. P.

RAWLS, J., 1971: A Theory of Justice, Oxford: U. P.

- 1980: «Kantian Constructivism in Moral Theory», The Journal of Philosophy, 77.

- 1993: Political Liberalism, New York: Columbia U. P.

- Collected Papers, S. Freeman (ed.), Cambridge: Harvard U. P.

- 2001: Justice as Fairness: A Briefer Restatement, Cambridge: Harvard U. P.

Ross, W. D., 1955: The Right and the Good, Oxford: Clarendon.

SAYRE-MCCorD, G., 1996: «Coherentist Epistemology and Moral Theory», en W. SinNOTTArmstrong (ed.), Moral Knowledge?, cit.

SCANLON, T. M., 1998: What We Owe to Each Other, Cambridge: Harvard U. P.

SCHauer, F., 2006: Profiles, Probabilities and Stereotypes, Cambridge: Harvard U. P.

SCHeFfler, S., 2003: «What is Egalitarianism?», Philosopby E Public Affairs, 31.

SHER, G., 1987: Desert, Princeton: U. P.

Titelbaum, M. G., 2008: «What Would a Rawlsian Ethos of Justice Look Like?», Philosophy E Public Affairs, 36. 